\title{
Cochrane
}

Library

Cochrane Database of Systematic Reviews

\section{Phototherapy for treating foot ulcers in people with diabetes} (Review)

Wang HT, Yuan JQ, Zhang B, Dong ML, Mao C, Hu D

Wang HT, Yuan JQ, Zhang B, Dong ML, Mao C, Hu D.

Phototherapy for treating foot ulcers in people with diabetes.

Cochrane Database of Systematic Reviews 2017, Issue 6. Art. No.: CD011979.

DOI: 10.1002/14651858.CD011979.pub2.

www.cochranelibrary.com 
TABLE OF CONTENTS

HEADER 1

ABSTRACT

PLAIN LANGUAGE SUMMARY

SUMMARY OF FINDINGS

BACKGROUND

OBJECTIVES

METHODS

RESULTS

Figure 1.

Figure 2.

Figure 3.

DISCUSSION

AUTHORS' CONCLUSIONS

ACKNOWLEDGEMENTS

REFERENCES

CHARACTERISTICS OF STUDIES

DATA AND ANALYSES

Analysis 1.1. Comparison 1 Phototherapy versus no phototherapy/placebo, Outcome 1 Proportion of wounds completely healed during follow-up (4 to 20 weeks).

Analysis 1.2. Comparison 1 Phototherapy versus no phototherapy/placebo, Outcome 2 Change in ulcer size in relative terms (percentage change in wound area).

Analysis 1.3. Comparison 1 Phototherapy versus no phototherapy/placebo, Outcome 3 Change in ulcer size in absolute terms (mean change in wound area).

Analysis 1.4. Comparison 1 Phototherapy versus no phototherapy/placebo, Outcome 4 Number of amputations at study end (20 weeks).

Analysis 2.1. Comparison 2 Phototherapy versus high-voltage pulsed current, Outcome 1 Proportion of wounds completely healed during follow-up.

APPENDICES

CONTRIBUTIONS OF AUTHORS

DECLARATIONS OF INTEREST

SOURCES OF SUPPORT

DIFFERENCES BETWEEN PROTOCOL AND REVIEW

INDEX TERMS 
[Intervention Review]

\title{
Phototherapy for treating foot ulcers in people with diabetes
}

\author{
Hong-Tao Wang ${ }^{1}$, Jin-Qiu Yuan², Bin Zhang ${ }^{3}$, Mao-Long Dong ${ }^{1}$, Chen Mao², Dahai Hu${ }^{1}$
}

1Burns Centre of PLA, Department of Burns and Cutaneous Surgery, Xijing Hospital, Fourth Military Medical University, Xi'an, China. 2Division of Epidemiology, The Jockey Club School of Public Health and Primary Care, The Chinese University of Hong Kong, Hong Kong SAR, China. ${ }^{3}$ Department of Dermatology and Venereology, Xinqiao Hospital, Third Military Medical University, Chongqing, China

Contact address: Dahai Hu, Burns Centre of PLA, Department of Burns and Cutaneous Surgery, Xijing Hospital, Fourth Military Medical University, 169, Changle West Road, Xi'an, Shanxi Province, China. hudahai2006@gmail.com.

Editorial group: Cochrane Wounds Group.

Publication status and date: New, published in Issue 6, 2017.

Citation: Wang HT, Yuan JQ, Zhang B, Dong ML, Mao C, Hu D. Phototherapy for treating foot ulcers in people with diabetes. Cochrane Database of Systematic Reviews 2017, Issue 6. Art. No.: CD011979. DOI: 10.1002/14651858.CD011979.pub2.

Copyright @ 2017 The Cochrane Collaboration. Published by John Wiley \& Sons, Ltd.

\section{A B S T R A C T}

\section{Background}

Foot ulcers are a disabling complication of diabetes that affect $15 \%$ to $25 \%$ of people with diabetes at some time in their lives. Phototherapy is a relatively new, non-invasive, and pain-free treatment method, which promotes the ulcer repair process through multiple mechanisms such as increased cell growth and vascular activity. Phototherapy may be used as an alternative approach for the treatment of foot ulcers in people with diabetes, but the evidence for its effect compared with placebo or other treatments has not yet been established.

\section{Objectives}

To assess the effects of phototherapy for the treatment of foot ulcers in people with diabetes.

\section{Search methods}

We searched the Cochrane Wounds Specialised Register (11 October 2016), the Cochrane Central Register of Controlled Trials (CENTRAL) (the Cochrane Library, 2016, Issue 10), Ovid MEDLINE (11 October 2016), Ovid MEDLINE (In-Process \& Other Non-Indexed Citations) (11 October 2016), Ovid Embase (11 October 2016), EBSCO CINAHL Plus (11 October 2016), and China National Knowledge Infrastructure (24 June 2017). We also searched clinical trials registries for ongoing and unpublished studies on 24 June 2017, and screened reference lists to identify additional studies. We used no restrictions with respect to language, date of publication, or study setting.

\section{Selection criteria}

Randomised controlled trials or cluster randomised controlled trials that 1) compared phototherapy with sham phototherapy, no phototherapy, or other physical therapy modalities, 2) compared different forms of phototherapy, or 3) compared phototherapy of different output power, wavelength, power density, or dose range, in adults with diabetes and an open foot ulcer of any severity, in any setting.

\section{Data collection and analysis}

Two review authors independently performed study selection, data extraction, and 'Risk of bias' assessment. We combined the study outcomes when appropriate.

\section{Main results}

Eight trials with 316 participants met the inclusion criteria. Most of the included studies were single-centre studies that were carried out in clinics or hospitals with a sample size ranging from 14 to 84 . We generally considered the included studies to be at unclear or high risk of bias, as they had one domain at high risk of bias, or three or more domains at unclear risk of bias. 
We did not identify any studies that reported valid data for time to complete wound healing. Meta-analysis of four studies including 116 participants indicated that participants receiving phototherapy may experience a greater proportion of wounds completely healed during follow-up compared with those receiving no phototherapy/placebo $(64.5 \%$ for the phototherapy group versus $37.0 \%$ for the no phototherapy/placebo group; risk ratio 1.57, 95\% confidence interval 1.08 to 2.28 ; low-quality evidence, downgraded for study limitations and imprecision). Two studies mentioned adverse events in the results; one study with 16 participants suggested that there were no devicerelated adverse events, and the other study with 14 participants suggested that there was no clear difference between phototherapy and placebo group.

Four studies reported change in ulcer size, but primarily due to high heterogeneity, they were not combined. Results from individual trials (including 16 participants to 84 participants) generally suggested that after two to four weeks of treatment phototherapy may result in a greater reduction in ulcer size but the quality of the evidence was low due to unclear risk of bias in the original trial and small sample size. We based the analyses for quality of life and amputations on only one study each ( 28 participants and 23 participants respectively); both outcomes showed no clear difference between the phototherapy group and the no phototherapy/placebo group.

\section{Authors' conclusions}

This systematic review of randomised trials suggested that phototherapy, when compared to no phototherapy/placebo, may increase the proportion of wounds completely healed during follow-up and may reduce wound size in people with diabetes, but there was no evidence that phototherapy improves quality of life. Due to the small sample size and methodological flaws in the original trials, the quality of the evidence was low, which reduces our confidence in these results. Large, well-designed randomised controlled trials are needed to confirm whether phototherapy could be an effective option for the treatment of foot ulcers in people with diabetes.

\section{PLAIN LANGUAGE SUMMARY}

\section{Phototherapy for treating foot ulcers in people with diabetes}

\section{Review question}

Phototherapy is a pain-free method of treatment that uses light to treat various medical conditions. We reviewed the evidence about phototherapy for foot ulcers in people with diabetes. We wanted to find out whether phototherapy speeds up wound healing and improves patients' quality of life, and whether there are any side effects.

\section{Background}

Foot ulcers are a disabling complication of diabetes that affect $15 \%$ to $25 \%$ of people with diabetes at some time in their lives. Diabetic foot ulcers are painful and prone to infection. Not all diabetic foot ulcers can be healed, which can ultimately lead to surgical removal of a limb. Phototherapy involves exposing the affected area to ultraviolet light, sometimes using lasers. This is thought to help ulcers heal through multiple mechanisms such as increased cell growth and blood vessel activity. It has been used as an alternative approach for healing foot ulcers in people with diabetes.

\section{Study characteristics}

We searched for randomised controlled trials comparing different phototherapies, or comparing phototherapy with other treatments or a placebo (sham treatment), for foot ulcers in adults with diabetes in October 2016. We included eight trials (316 participants). Most studies were undertaken in clinics or hospitals and had small numbers of participants (14 to 84). The average age in the included studies was from 53 to 68 years, and the ratio of females to males was 0.46 to 1.88 . The included studies compared phototherapy with placebo or no phototherapy, on top of usual care (usual care could include treatments such as dressings, antibiotics, or wound cleaning). Treatment times ranged from 15 days to 20 weeks.

\section{Key results}

The results suggested that phototherapy, when compared to no phototherapy or a placebo, may increase the proportion of wounds completely healed during follow-up and reduce wound size. However, as the included studies involved small numbers of participants and had drawbacks in study methods, our confidence in these results is limited. We did not find sufficient evidence that the potential harms or incidence of amputations differed between the phototherapy group and the no phototherapy/placebo group.

\section{Quality of the evidence}

We judged the quality of the evidence to be low due to a lack of data and risk of the study results being biased. Further high-quality studies are needed to confirm the benefits and harms of phototherapy.

This plain language summary is up to date as of 26 October 2016. 
SUMMARY OF FINDINGS

Summary of findings for the main comparison. Phototherapy compared with placebo/no phototherapy for foot ulcers in people with diabetes

Phototherapy compared with placebo/no phototherapy for foot ulcers in people with diabetes

Patient or population: Diabetes with foot ulcers

Settings: Clinics and hospitals

Intervention: Phototherapy

Comparison: Placebo/no phototherapy

\begin{tabular}{|c|c|c|c|c|c|c|}
\hline \multirow[t]{3}{*}{ Outcomes } & \multicolumn{2}{|c|}{$\begin{array}{l}\text { Anticipated absolute effects }{ }^{\star}(95 \% \\
\mathrm{Cl})\end{array}$} & \multirow[t]{3}{*}{$\begin{array}{l}\text { Relative effect } \\
(95 \% \mathrm{CI})\end{array}$} & \multirow{3}{*}{$\begin{array}{l}\text { No of Partici- } \\
\text { pants } \\
\text { (studies) }\end{array}$} & \multirow{3}{*}{$\begin{array}{l}\text { Quality of the } \\
\text { evidence } \\
\text { (GRADE) }\end{array}$} & \multirow[t]{3}{*}{ Comments } \\
\hline & $\begin{array}{l}\text { Assumed ab- } \\
\text { solute effect }\end{array}$ & $\begin{array}{l}\text { Corresponding } \\
\text { absolute effect }\end{array}$ & & & & \\
\hline & $\begin{array}{l}\text { Placebo/no } \\
\text { phototherapy }\end{array}$ & Phototherapy & & & & \\
\hline $\begin{array}{l}\text { Wound healing - pro- } \\
\text { portion of wounds } \\
\text { completely healed dur- } \\
\text { ing follow-up }\end{array}$ & 330 per 1000 & $\begin{array}{l}\mathbf{5 6 8} \text { per } \mathbf{1 0 0 0} \\
(383 \text { to } 845)\end{array}$ & $\begin{array}{l}\text { RR } 1.57 \\
\text { (1.08 to } 2.28)\end{array}$ & 116 (4 studies) & $\begin{array}{l}\oplus \oplus \ominus \ominus \\
\text { low }^{1}\end{array}$ & \\
\hline Adverse events & See comment & See comment & See comment & See comment & See comment & $\begin{array}{l}\text { In Landau 2011, there were no device-related } \\
\text { adverse events. In Londahl } 2013 \text {, the authors } \\
\text { suggested that there was no difference in ad- } \\
\text { verse events between intervention and con- } \\
\text { trol groups, but the number of adverse events } \\
\text { was not reported. }\end{array}$ \\
\hline
\end{tabular}

*The basis for the assumed absolute effect (e.g. the median control group risk across studies) is provided in footnotes. The corresponding absolute effect (and its $95 \%$ confidence interval) is based on the assumed absolute effect in the comparison group and the relative effect of the intervention (and its $95 \% \mathrm{Cl}$ ).

Cl: confidence interval; RR: risk ratio.

GRADE Working Group grades of evidence 
High quality: Further research is very unlikely to change our confidence in the estimate of effect.

Moderate quality: Further research is likely to have an important impact on our confidence in the estimate of effect and may change the estimate.

Low quality: Further research is very likely to have an important impact on our confidence in the estimate of effect and is likely to change the estimate.

Very low quality: We are very uncertain about the estimate.

1Downgraded one level for study limitations (high risk of bias for incomplete outcome data in two studies and potential influence of imbalance in baseline characteristics in one study) and one level for imprecision (small sample size). 


\section{B A C K G R O U N D}

\section{Description of the condition}

Diabetes mellitus is a group of disorders characterised by raised blood glucose levels. It impairs quality of life, and has a strong association with heart disease, stroke, and death (Barr 2007; Ellen 2007). Owing to a rapidly aging population, the number of people with diabetes is increasing throughout the world. The World Health Organization estimated that the global prevalence of diabetes was $9 \%$ among adults in 2014, and that diabetes will be the seventhleading cause of death in 2030 (Mathers 2006; WHO 2014).

Foot ulcers, defined as wounds extending through the full thickness of the skin below the level of the ankle (Apelqvist 2000a; Lipsky 2012), are a disabling complication of diabetes. People with diabetes are at considerable risk of developing foot ulcers. It has been estimated that $15 \%$ to $25 \%$ of people with diabetes will be affected by foot ulcers at some time in their lives (Boulton 2008; Singh 2005). The worldwide prevalence of foot ulcers amongst people with diabetes varies by country, with about $2 \%$ in highincome countries, compared with about $15 \%$ to $20 \%$ in low and middle income countries (Margolis 2011; Shailesh 2012; Tseng 2003). The high risk of foot ulceration in people with diabetes is the result of a complex combination of extrinsic and intrinsic factors. Firstly, peripheral insensitivity due to neuropathy may lead to abnormal loading and increased pressure of the foot, which in turn causes tissue damage (Boulton 2000). The impaired sensation may also reduce a person's awareness of potentially dangerous foreign bodies and injuries. Secondly, the additional presence of peripheral vascular disease may lead to poor healing of the damaged tissue (Apelqvist 2000a; Boulton 2000). Limited joint mobility, foot deformation, and poorly fitting footwear may further increase the risk of foot ulcers in people with diabetes (Apelqvist 2000a).

Diabetic foot problems have a significant impact on a person's quality of life. It often takes several weeks or months for ulcers to heal, even with timely and intensive treatment (Zimny 2002). A substantial proportion of ulcers do not heal, and lower-extremity amputations are performed (Reiber 2001). Evidence has shown that people with diabetes have a 10 - to 20 -fold increased risk of losing a part or full lower limb due to non-traumatic amputation when compared with people without diabetes (Morris 1998; Wrobel 2001). Approximately $30 \%$ to $60 \%$ of all amputations of the lower extremity are performed in people with diabetes, and over $85 \%$ of these amputations are preceded by a foot ulcer deteriorating to deep infection or gangrene (Apelqvist 2000b; CDC 2014; ZieglerGraham 2008).

Foot problems in people with diabetes also have a significant financial impact on national health systems around the world. The direct costs of treatment for foot ulcers in people with diabetes include wound dressings, antibiotics, surgery, specialist footwear, staff costs, and hospital admissions (Stockl 2004). The costs other than treatment, including the costs associated with preventive efforts, rehabilitation, home care, and the loss of work time and productivity, are also high. In the United States, ulcer care adds around USD 9 billion to 13 billion to the direct yearly costs associated with diabetes itself (Rice 2014).

\section{Description of the intervention}

Though a variety of therapeutic methods such as wound cleansing, debridement, antibiotics, off-loading and skin grafting are available for the treatment of foot ulcers in people with diabetes, the results of treatment are often unsatisfactory (Khanolkar 2008). Phototherapy is a relatively new, non-invasive, and pain-free treatment method that has received clearance from the US Food and Drug Administration for its beneficial effects on tissue healing and pain relief (MedX Health 2012; Vargas 2005). Phototherapy uses light for therapeutic purposes. Accumulating evidence indicates that phototherapy may promote the repair processes of skin, ligament, bone, tendon, and cartilage (Fung 2002; Kana 1981; Posten 2005; Trelles 1987).

Technical parameters determining the therapeutic effects of phototherapy include output power, wavelength, power density, and dose range (Posten 2005; Verma 2012). For wound healing, the commonly used form of phototherapy is low-level laser therapy (LLLT), which is primarily defined as power with a range of 0.001 to $0.1 \mathrm{~W}$, a wavelength between 300 and $10,600 \mathrm{~nm}$, a pulse rate of 0 to $5000 \mathrm{~Hz}$, intensity of 0.01 to $100 \mathrm{~W} / \mathrm{cm}^{2}$, and a dose of 0.01 to $100 \mathrm{~J} / \mathrm{cm}$ (Posten 2005; Verma 2012). In addition to LLLT, a relatively new type of phototherapy, light-emitting diode (LED), is also used for wound healing (El-Deen 2014; MedX Health 2015). This type of phototherapy provides a more superficial, even distribution of energy with lower power density and longer treatment time than LLLT (MedX Health 2015). There is currently no recommendation about the standard procedure of phototherapy for treating foot ulcers in people with diabetes. In some previous clinical studies, phototherapy was performed from approximately 4 to 50 minutes per time, twice per week to twice daily, for a total of 15 to 90 days (Beckmann 2014).

\section{How the intervention might work}

It has been shown that phototherapy can directly supply biostimulative light energy to cells, thereby stimulating molecules and atoms of cells without causing significant increase in tissue temperature (Basford 1989; Karu 1989). The effect is closely related to photochemical reactions in the cells. The possible mechanisms for phototherapy to promote the ulcer repair process in people with diabetes are as follows (for a definition of technical terms, please see the glossary in Appendix 1).

- Increased metabolic activity. Phototherapy may stimulate more efficient electron transfer in the cytochrome oxidase pathway, thereby increasing the capacity of mitochondria to generate adenosine triphosphate (ATP). Increased ATP in turn increases the energy supply for the cell's metabolic processes (Karu 2004; Yu 1997).

- Rapid cell growth. In vitro and in vivo studies have suggested that laser light accelerates cellular reproduction and growth (Kreisler 2002; Lubart 1992; Schindl 2003). These effects may be attributable to the stimulation of the oxidative metabolic pathway and the increase in overall cell metabolism (Chen 2008).

- Angiogenesis. A number of animal studies have suggested that LLLT may promote the physiological process through which new blood vessels form from pre-existing vessels (Cury 2013). This is particularly important for people with diabetes, who are often associated with peripheral vascular disease. 
- Increased vascular activity. In vitro data have suggested that laser light induces temporary vasodilation, increasing blood flow to the injured area (Gorshkova 2013).

- Faster wound healing. Lasers may promote wound healing by stimulating fibroblast development, accelerating collagen synthesis in damaged tissue, and increasing the release of growth factor (Cury 2013; Dourado 2011; Pereira 2002).

\section{Why it is important to do this review}

Given the huge disease burden and the difficulty in treatment, the management of foot ulcers in people with diabetes has become a major challenge worldwide. Phototherapy may be used as an alternative approach for healing ulcers. Though some potential mechanisms of phototherapy have been investigated, the exact process of healing with phototherapy remains unclear. To date a number of randomised controlled trials (RCTs) have been performed to evaluate the efficacy of phototherapy for treating foot ulcers in people with diabetes (Kajagar 2012; Kaviani 2011; Minatel 2009; Schindl 1998; Zhang 2012), but few systematic reviews have been undertaken to summarise the related evidence. In 2014, Beckmann and colleagues performed a systematic literature review of phototherapy for diabetic foot ulcers (Beckmann 2014); however, this was not carried out as a standard systematic review, and some key steps like quality assessment were not undertaken. A Cochrane systematic review would provide decision makers with the best evidence on the effectiveness of phototherapy for treating foot ulcers in people with diabetes.

\section{OB JECTIVES}

To assess the effects of phototherapy for the treatment of foot ulcers in people with diabetes.

\section{METHODS}

\section{Criteria for considering studies for this review}

\section{Types of studies}

RCTs or cluster RCTs, irrespective of publication status or language.

\section{Types of participants}

Adults with Type I or Type II diabetes with an open foot ulcer of any severity, in any setting. We placed no restriction on the aetiology of the ulcer; trials recruiting people with diabetes with ulcers of neuropathic, ischaemic, or neuroischaemic causes were all eligible for inclusion.

\section{Types of interventions}

LLLT, LED, and other forms of phototherapy were eligible for inclusion. There was no limitation on phototherapy irradiance, wavelength, and frequency of treatment. Participants could receive standard treatment for diabetic foot ulcers such as wound cleansing, debridement, and antibiotics, but the treatment must have been balanced between intervention group and control group (i.e. the phototherapy would be the only systematic difference between groups). We included the following comparisons.

- Phototherapy compared with sham phototherapy, no phototherapy (usual care alone), or other physical therapy modalities (such as electronic stimulations, electromagnetics, and ultrasound).
- Comparisons of different forms of phototherapy.

- Comparisons of phototherapy of different output power, wavelength, power density, or dose range.

\section{Types of outcome measures}

\section{Primary outcomes}

1. Complete wound healing. A range of different methods of measuring and reporting this outcome are used in studies. We reported the authors' definitions of complete wound healing where possible. We considered RCTs that reported one or more of the following outcomes to provide the most relevant and rigorous measures of wound healing:

a. time to complete wound healing (unit: weeks or days; correctly analysed using survival, time-to-event approaches, or mean time to healing if it was clear that all wounds were healed during follow-up);

b. proportion of wounds completely healed during follow-up.

2. Number of adverse events: all adverse events, treatment-related adverse events, and any specific adverse events reported in the trials.

\section{Secondary outcomes}

1. Change in ulcer size expressed in either absolute (unit: $\mathrm{mm}^{2}$ ) or relative terms (unit: \%).

2. Participant health-related quality of life/health status (measured using a standardised generic questionnaire such as EQ-5D, SF-36, SF-12, SF-6, Nottingham Health Profile, visual analogue scale, or wound-specific questionnaires such as the Cardiff Wound Impact Schedule). We did not include ad hoc measures of quality of life that were not likely to be validated and would not be common to multiple trials.

3. Number and level (foot, at the ankle, below the knee, at the knee, above the knee, and at the hip) of amputations at study end.

\section{Search methods for identification of studies}

We carried out the literature search according to methods stated in the published protocol (Wang 2015).

\section{Electronic searches}

We searched the following electronic databases to identify relevant RCTs:

- the Cochrane Wounds Specialised Register (searched 11 October 2016);

- the Cochrane Central Register of Controlled Trials (CENTRAL) (the Cochrane Library, 2016, Issue 10);

- Ovid MEDLINE (1946 to 11 October 2016);

- Ovid MEDLINE (In-Process \& Other Non-Indexed Citations) (searched 11 October 2016);

- Ovid Embase (1974 to 11 October 2016);

- EBSCO Cumulative Index to Nursing and Allied Health Literature (CINAHL Plus) (1937 to 11 October 2016);

- China National Knowledge Infrastructure (CNKI) (1990 to 24 June 2017).

The detailed search strategies are presented in Appendix 2. We combined the Ovid MEDLINE search with the Cochrane Highly 
Sensitive Search Strategy for identifying randomised trials in MEDLINE: sensitivity- and precision-maximising version (2008 revision) (Lefebvre 2011). We combined the Embase search with the Ovid Embase filter developed by the UK Cochrane Centre (Lefebvre 2011). We combined the CINAHL searches with the trial filters developed by the Scottish Intercollegiate Guidelines Network (SIGN 2017). There were no restrictions with respect to language, date of publication, or study setting.

\section{Searching other resources}

We searched the following clinical trial registers for ongoing and unpublished trials:

- ISRCTN registry (www.isrctn.com/) (searched 24 June 2017);

- World Health Organization International Clinical Trials Registry Platform (WHO ICTRP) (apps.who.int/trialsearch/) (searched 24 June 2017);

- ClinicalTrials.gov (clinicaltrials.gov) (searched 24 June 2017);

- Chinese Clinical Trial Register (www.chictr.org.cn/enindex.aspx) (searched 24 June 2017).

We also manually searched the reference lists of the included studies and previous reviews, and contacted manufacturers in an effort to identify additional eligible studies.

\section{Data collection and analysis}

We carried out data collection and analysis according to the methods stated in the published protocol (Wang 2015).

\section{Selection of studies}

Two review authors (HW, JY) independently assessed the study eligibility according to the predefined inclusion and exclusion criteria. All citations were initially imported into reference management software, and duplicate citations were removed automatically. We screened the titles and abstracts to determine the eligibility of the remaining studies, retrieving the full texts of potentially eligible studies for assessment. Any disagreements were resolved by discussion with a third review author (DH). We collated multiple reports of a same study so that each study, rather than each report, was the unit of interest in the review. We completed a PRISMA flow chart to summarise the process (Liberati 2009).

\section{Data extraction and management}

Two review authors (HW, JY) independently extracted data using a standard form pre-designed for this review. We consulted the authors of original studies for missing information where necessary. We extracted the following data:

- study characteristics (e.g. authors, location, title);

- care setting;

- participant characteristics (number of participants; participant age, sex, race, diabetes mellitus duration, foot ulcer duration and size, and ulcer aetiology);

- intervention and comparisons (technical parameters of phototherapy, treatment duration, other treatment received);

- risk of bias information (randomisation, sequence concealment, blinding, incomplete outcome data, selective reporting);

- results on our outcomes of interest (e.g. point estimates, standard deviation);
- length of follow-up period.

\section{Assessment of risk of bias in included studies}

Two review authors (HW, JY) independently evaluated the risk of bias of the included studies using Cochrane's tool for assessing risk of bias (Higgins 2011b). We categorised the risk of bias as low, unclear, or high for each domain. The domains for risk of bias are as follows (Higgins 2011b):

- selection bias (sequence generation and allocation concealment);

- performance bias (blinding of participants and personnel);

- detection bias (blinding of outcome assessment);

- attrition bias (incomplete outcome data);

- reporting bias (selective reporting);

- other bias (design-specific risks of bias for cluster RCTs, and other problems).

We have presented a detailed description of the tool used for assessing bias in the above domains in Appendix 3. We applied the results of the 'Risk of bias' assessment to the sensitivity analysis, evaluation of the quality of the evidence, and in formulating the conclusions of the review.

\section{Measures of treatment effect}

We presented dichotomous outcomes, such as number of ulcers completely healed and adverse events, as risk ratios (RRs) and corresponding $95 \% \mathrm{Cls}$. For continuous outcomes, we used mean differences (MD) and 95\% Cls as the measure of treatment effects. We planned to present time-to-event data as hazard ratios with corresponding $95 \% \mathrm{Cls}$, however no such data were reported in the included studies.

\section{Unit of analysis issues}

The primary unit of analysis was the participant. We checked the level at which randomisation occurred (individual ulcers, participants, or clusters (wards, clinics, clinicians)), and whether the analysis of original trials properly took into account the level of randomisation. When we included trials that evaluated multiple ulcers on the same participant or other cluster studies, we planned to extract the direct estimate from the analysis that properly accounts for the unit of analysis issues (e.g. multilevel model analysis or variance components analysis). We intended to combine effect estimates and their standard errors using the generic inversevariance method (Higgins 2011a). If we found unit of analysis issues for which we were unable to adjust, we planned to report them as part of the 'Risk of bias' assessment. However, we did not identify any included studies with unit of analysis issues.

\section{Dealing with missing data}

We contacted the authors of the original studies to clarify methodological ambiguities or to obtain additional results not available from the published data, or both. For dichotomous healing data, where a study presented data on the number of healed ulcers, we assumed that the wounds of randomised participants that were not included in an analysis did not heal. Where a trial did not specify participant group numbers prior to dropout, we presented only complete-case data (Higgins 2011a). Data on secondary outcomes were analysed using complete cases only. 


\section{Assessment of heterogeneity}

We considered clinical, methodological, and statistical heterogeneity. We evaluated clinical heterogeneity by considering the variability in important factors (age, duration of diabetes, duration of ulcer, ulcer size, ulcer aetiology, intervention and outcome characteristics) among trials. We assessed statistical heterogeneity among studies with the $\mathrm{I}^{2}$ statistic (Higgins 2003). We determined the level of statistical heterogeneity per the recommendations found in the Cochrane Handbook for Systematic Reviews of Interventions as follows (Higgins 2011a).

- $0 \%$ to $40 \%$ : might not be important.

- $30 \%$ to $60 \%$ : may represent moderate heterogeneity.

- $50 \%$ to $90 \%$ : may represent substantial heterogeneity.

- $75 \%$ to $100 \%$ : considerable heterogeneity.

\section{Assessment of reporting biases}

Had 10 or more studies been included in the meta-analysis, we would have assessed the risk of publication bias using a funnel plot (Thornton 2000; Trautner 1996). We intended to test funnel plot asymmetry by Egger's test (Egger 1997).

\section{Data synthesis}

We combined details of included studies in a narrative review according to comparison between intervention and comparator, population, and time point of the outcome measurement. We used the fixed-effect model for combining data as it was reasonable to assume that studies were estimating the similar underlying treatment effect, in terms of intervention, study population, and methods. The result of the random-effects model was similar to the fixed-effect model as the statistical heterogeneity was minimal.

\section{Sensitivity analysis}

We undertook sensitivity analyses to assess the robustness of our results according to the risk of bias of the included studies. Where possible, we excluded from any meta-analysis studies that scored high risk of bias for one or more domains according to Cochrane's tool for assessing risk of bias.

\section{'Summary of findings' table and GRADE}

We used a 'Summary of findings' table to summarise the treatment effects and quality of the evidence for the main comparisons and primary outcomes.

We evaluated the strength of evidence for all study outcomes using GRADE (Guyatt 2008a; Guyatt 2008b). We initially ranked the evidence as high-quality because the estimates were based on randomised trials. We downgraded the quality of the evidence for the following factors: study limitations, inconsistency of results, indirectness of evidence, imprecision, and publication bias. We presented the quality of the evidence as follows (Guyatt 2008b).

- High: further research is very unlikely to change our confidence in the estimated effect.

- Moderate: further research is likely to have an important impact on our confidence in the estimated effect and may change the estimate.

- Low: further research is very likely to have an important impact on our confidence in the estimated effect and is likely to change the estimate.

- Very low: we are very uncertain about the estimate.

\section{RES U L T S}

\section{Description of studies}

See: Characteristics of included studies; Characteristics of excluded studies; Characteristics of studies awaiting classification; Characteristics of ongoing studies

\section{Results of the search}

The literature search yielded 446 potentially eligible citations, of which 376 were identified from electronic databases and 70 from other sources. We excluded 425 studies after screening titles and abstracts. We evaluated the full texts of the 21 remaining citations, of which 10 studies were considered as ineligible (see Characteristics of excluded studies table); two studies were ongoing studies (see Characteristics of ongoing studies table); one study pending full-text retrieval is awaiting further classification (see Characteristics of studies awaiting classification table), and eight studies were included in the review (see Characteristics of included studies table). See flow chart of study selection in Figure 1. 
Figure 1. Flow chart of study selection.

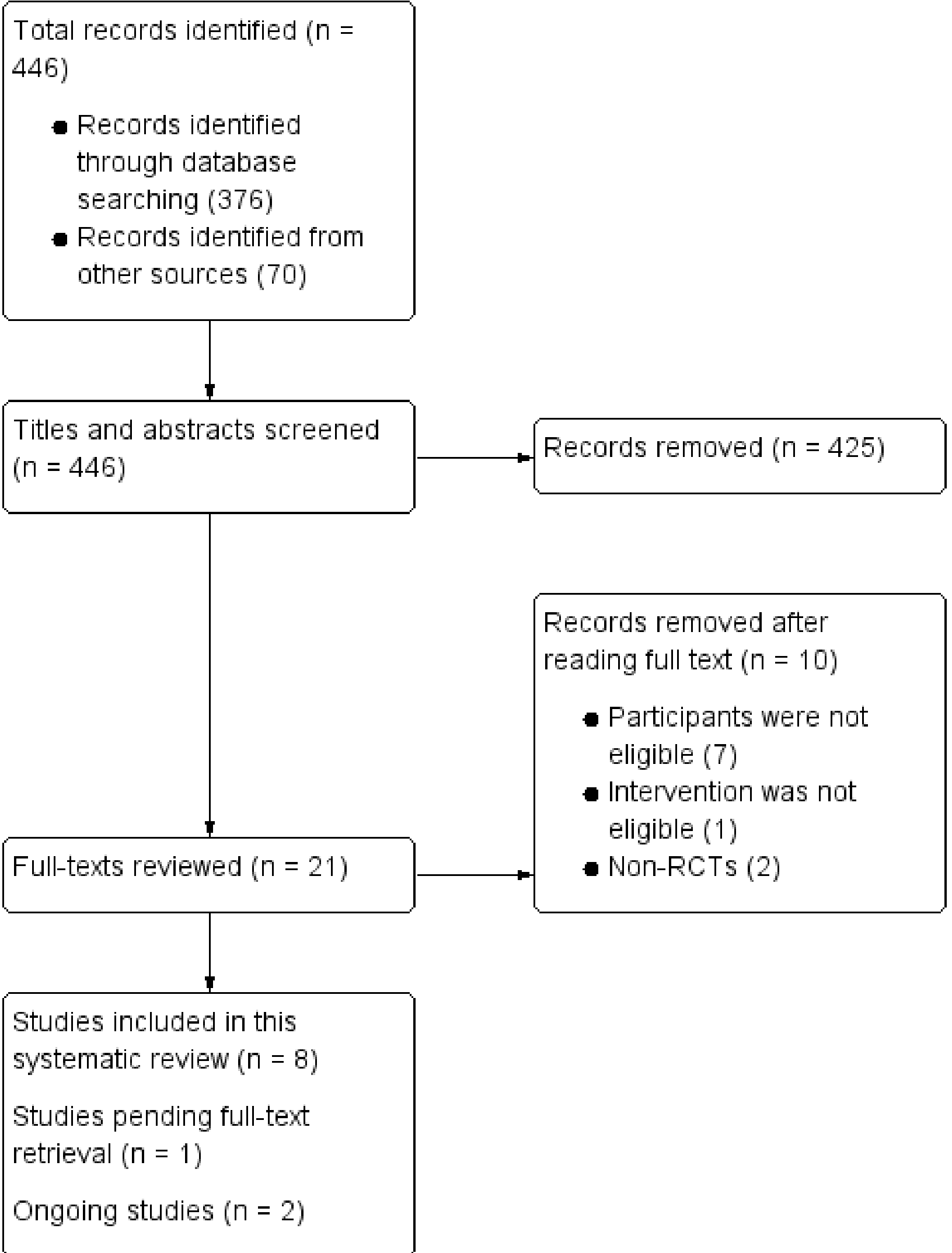




\section{Included studies}

Eight RCTs with 316 participants met the inclusion criteria for this systematic review (see Characteristics of included studies table). All of the included studies were single-centre studies except for Londahl 2013, which was a multicentre trial. Most trials had two study arms except for Ortíz 2014, which had three arms. The included studies were generally small, with a sample size from 14 to 84 . The included studies were performed in China (Zhang 2012; Zhang 2013; Zhao 2005), Iran (Kaviani 2011), India (Kajagar 2012 ), Colombia (Ortíz 2014 ), Israel (Landau 2011), and Sweden (Londahl 2013). Most studies were performed in clinics or hospitals (Kajagar 2012; Kaviani 2011; Landau 2011; Zhang 2012; Zhang 2013; Zhao 2005); the information about setting was not reported in two studies (Londahl 2013; Ortíz 2014). Most included studies were published as journal articles except for Londahl 2013, which was retrieved from a conference abstract. As for funding sources, two studies were funded by government or university (Kaviani 2011; Ortíz 2014), one by a commercial company (Landau 2011), and the funding sources were not reported in other studies (Kajagar 2012; Londahl 2013; Zhang 2012; Zhang 2013; Zhao 2005).

\section{Participants}

In the seven studies that reported age (Kajagar 2012; Kaviani 2011; Landau 2011; Ortíz 2014; Zhang 2012; Zhang 2013; Zhao 2005), the average age of included participants was between 53 and 68 years. Six studies reported the gender of included participants (Kajagar 2012; Kaviani 2011; Landau 2011; Ortíz 2014; Zhang 2012; Zhao 2005), showing a ratio of females to males of 0.46 to 1.88 . In the four studies that reported the duration of diabetes (Kaviani 2011; Ortíz 2014; Zhang 2013; Zhao 2005), the mean duration of diabetes of included participants was from 7.1 years to 19.2 years. Four studies reported ulcer duration (Kajagar 2012; Kaviani 2011; Londahl 2013; Ortíz 2014), showing a median ulcer duration of 4.5 weeks to 46 weeks. In the four studies that reported ulcer size at baseline (Kajagar 2012; Kaviani 2011; Landau 2011; Zhao 2005), the average ulcer size was from $0.57 \mathrm{~cm}^{2}$ to $26.8 \mathrm{~cm}^{2}$. Six studies reported the Wagner classification of ulcer (Kajagar 2012; Kaviani 2011; Landau 2011; Londahl 2013; Ortíz 2014; Zhang 2013). All studies included people with stage I to II ulcers, except Zhang 2013, which included people with stage II to VI ulcers. No studies reported the ulcer aetiology of all included participants, except Kajagar 2012, which reported that $9(26.47 \%)$ participants in the phototherapy group and $6(17.64 \%)$ participants in the control group presented with peripheral neuropathy.

\section{Interventions}

Three trials compared phototherapy plus usual care with placebo plus usual care (Kaviani 2011; Landau 2011; Londahl 2013), and five studies compared phototherapy plus usual care with usual care (Kajagar 2012; Ortíz 2014; Zhang 2012; Zhang 2013; Zhao 2005). The study by Ortíz and colleagues also compared phototherapy plus usual care with high-voltage pulsed current plus usual care (Ortíz 2014). Therefore, we included this study under phototherapy versus no phototherapy/placebo and under phototherapy versus highvoltage pulsed current. The phototherapies used in the included trials included visible red light (Kaviani 2011; Ortíz 2014; Zhang 2012; Zhang 2013), visible red and near-infrared light (Londahl 2013), visible light (Landau 2011), and a combination of farinfrared light and ultraviolet light (Zhao 2005). The participants in the intervention and control arms in the included trials generally received usual care, which included debridement, topical treatment, wound dressing, oral antibiotics, or contact cast immobilisation (when necessary). The treatment duration of the included studies was from 15 days to 20 weeks.

\section{Outcomes}

Two studies reported the time to complete wound healing (Kaviani 2011; Landau 2011), but the data may not be reliable because not all of the ulcers were healed at study end. Four studies reported the proportion of wounds completely healed during follow-up (Kaviani 2011; Landau 2011; Ortíz 2014; Zhang 2012). Two studies mentioned adverse events (Landau 2011; Londahl 2013). Four studies reported change in ulcer size (Kajagar 2012; Kaviani 2011; Landau 2011; Zhang 2013), three of which reported this information in relative terms (Kaviani 2011; Landau 2011; Zhang 2013), and one in absolute terms (Kajagar 2012). Ortíz 2014 evaluated quality of life by EQ-5D self report questionnaire on a 0 to 100 scale (EQ visual analogue scale). Only one study reported the number of amputations at study end (Kaviani 2011).

\section{Excluded studies}

We excluded 10 studies from this systematic review: in seven studies the included participants were not people with diabetes and foot ulcers (Hart 2004; ISRCTN21741608; Minatel 2009; Nawfar 2011; Saied 2011; Schindl 1998; Schindl 2002); the design of two studies was not RCT (Chi 2002; Rinaldi 1993); and in the study by Minatel and colleagues the intervention was not phototherapy (Minatel 2010).

\section{Risk of bias in included studies}

We generally considered the included studies as at unclear or high risk of bias, as they either had one domain at high risk of bias (Kaviani 2011; Landau 2011; Ortíz 2014), or they had three or more domains at unclear risk of bias (Kajagar 2012; Londahl 2013; Zhang 2012; Zhang 2013; Zhao 2005). (See Characteristics of included studies; Figure 2; Figure 3.) 
Figure 2. Risk of bias graph: review authors' judgements about each risk of bias item presented as percentages across all included studies.

Random sequence generation (selection bias)

Allocation concealment (selection bias)

Blinding of participants and personnel (performance bias)

Blinding of outcome assessment (detection bias)

Incomplete outcome data (attrition bias)

Selective reporting (reporting bias)

Other bias

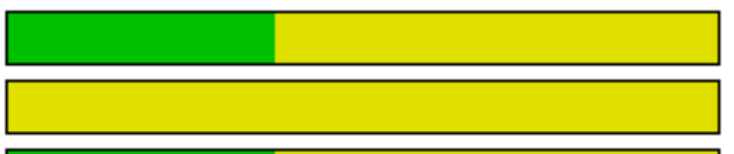

L

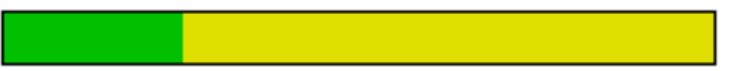

L
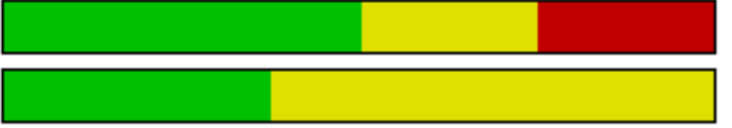

\begin{tabular}{|lllll|}
\hline $0 \%$ & $25 \%$ & $50 \%$ & $75 \%$ & $100 \%$
\end{tabular}


Figure 3. Risk of bias summary: review authors' judgements about each risk of bias item for each included study.

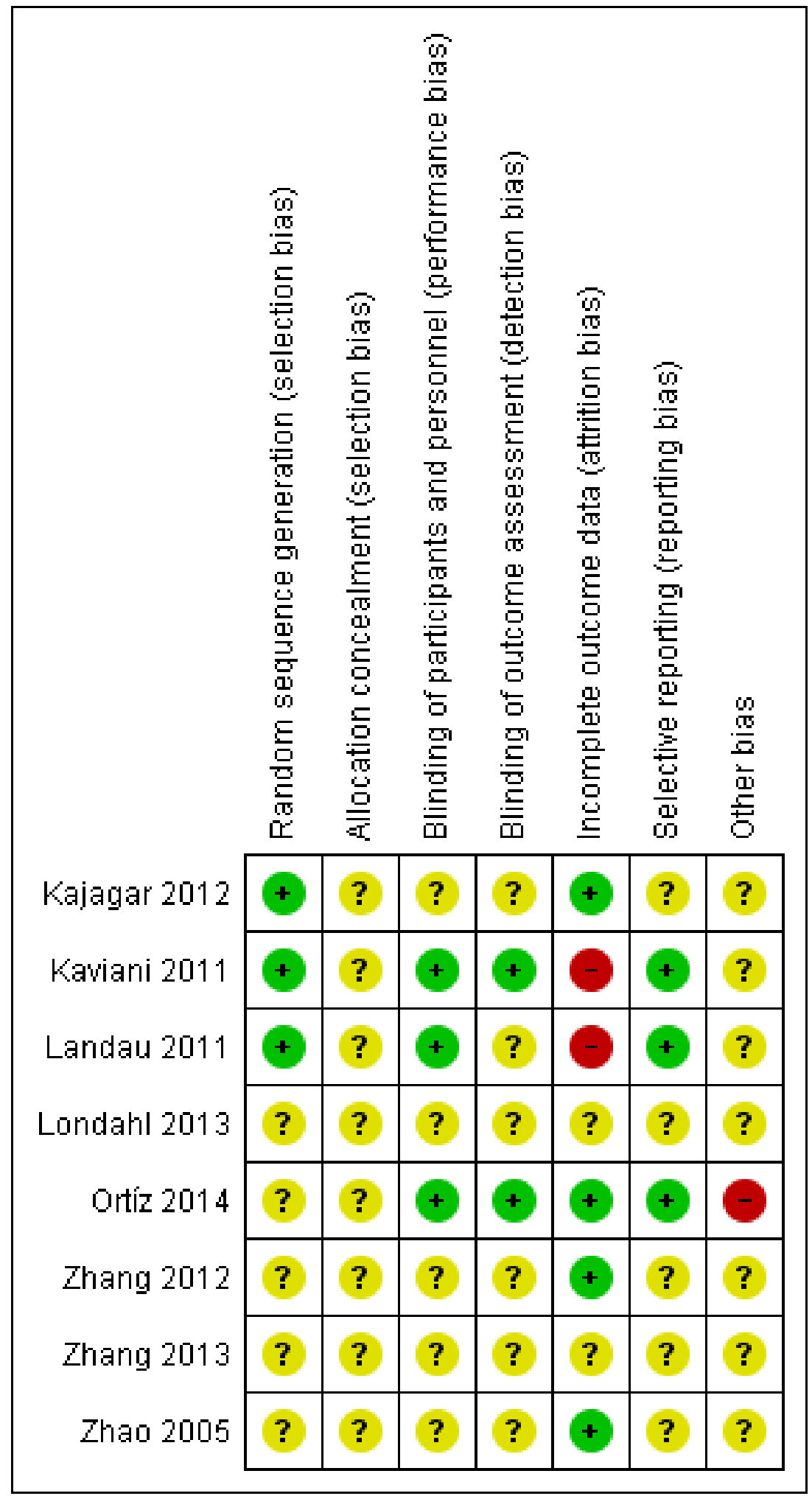

\section{Allocation}

\section{Adequacy of randomisation process}

All of the included studies were described as "randomised". Three studies reported the randomisation methods in detail, therefore we judged them to be at low risk of bias for this domain (Kajagar 2012; Kaviani 2011; Landau 2011). The remaining five studies did not report the detailed randomisation methods, hence we judged them to be at unclear risk of bias for this domain. 


\section{Allocation concealment}

As none of the included studies reported the allocation procedure, we judged them all to be at unclear risk of bias for this domain.

\section{Blinding}

\section{Blinding of participants and personnel}

Three studies were double-blind studies, and the details for blinding were reported, therefore we judged them as being at low risk of bias (Kaviani 2011; Landau 2011; Ortíz 2014). We judged the remaining five studies as at unclear risk of bias, as there was no mention of how blinding of participants and personnel was implemented (Kajagar 2012; Londahl 2013; Zhang 2012; Zhang 2013; Zhao 2005).

\section{Blinding of outcome assessment}

The study by Kaviani and colleagues suggested that the outcomes were assessed by two physicians blinded to treatment (Kaviani 2011). The protocol for the study by Ortíz and colleagues suggested that the outcome assessment was blinded (Ortíz 2014). We judged these two studies as at low risk for this domain (Kaviani 2011; Ortíz 2014). We judged the remaining studies as being at unclear risk of bias because there was no mention of how blinding of outcome assessment was implemented.

\section{Incomplete outcome data}

We judged the study by Kaviani and colleagues and the study by Landau and colleagues as being at high risk of bias because the reasons for missing outcome data were likely to be related to the outcome (Kaviani 2011; Landau 2011). We judged three studies to be at low risk in this domain because all randomised patients were included in data analysis (Kajagar 2012; Zhang 2012; Zhao 2005). We assessed the study by Ortíz and colleagues as at low risk of bias because this study applied intention-to-treat analysis (Ortíz 2014). We considered the remaining two studies to be at unclear risk of bias for this domain (Londahl 2013; Zhang 2013).

\section{Selective reporting}

We considered the study by Kaviani and colleagues and the study by Landau and colleagues to be at low risk of bias based on the study report, however we did not obtain the study protocols (Kaviani 2011; Landau 2011). We judged the study by Ortíz and colleagues as being at low risk of bias based on the study protocol (Ortíz 2014).

\section{Other potential sources of bias}

We assessed all studies as being at unclear risk of bias, as there was generally insufficient information to judge whether an important risk of bias existed, except for the study by Ortíz and colleagues (Ortíz 2014), which we considered to be at high risk of bias because there appeared to be an imbalance between intervention group and control group in total ulcer size and ulcer duration.

\section{Effects of interventions}

See: Summary of findings for the main comparison Phototherapy compared with placebo/no phototherapy for foot ulcers in people with diabetes

\section{Comparison 1. Phototherapy compared with placebo/no phototherapy}

\section{Primary outcome}

\section{Wound healing - time to complete wound healing}

We identified no studies that reported valid data for this outcome. Although Kaviani 2011 and Landau 2011 reported the mean or median time to wound closure, the assessment for the ulcer healing time was not reliable, and we did not include the data in quantitative analysis because not all of the ulcers were healed.

\section{Wound healing - proportion of wounds completely healed during follow-up}

Four studies including 116 participants contributed to the evaluation of proportion of wounds completely healed during follow-up (Kajagar 2012; Landau 2011; Ortíz 2014; Zhang 2012). The follow-up time of these four studies was 4 weeks in Zhang 2012, 12 weeks in Landau 2011, 16 weeks in Ortíz 2014, and 20 weeks in Kaviani 2011. All of the ulcers in the four studies were in stage I to II according to the Wagner classification. We pooled the four studies with a fixed-effect model. Meta-analysis indicated that the phototherapy group had a higher proportion of wounds completely healed during follow-up compared with the control group $(64.5 \%$ for the phototherapy group versus $37.0 \%$ for the control group; RR $1.57,95 \% \mathrm{Cl} 1.08$ to $2.28 ; \mathrm{I}^{2}=0 \%$ ) (see Analysis 1.1 ). The quality of the evidence was low due to high risk of bias for incomplete outcome data and a wide confidence interval for the estimate.

\section{Number of adverse events}

Two studies mentioned adverse events in the results (Landau 2011; Londahl 2013). Landau 2011 reported no device-related adverse events. In Londahl 2013, which was a conference abstract, the authors suggested that there was no difference in adverse events between the phototherapy group and the placebo group, however the number of adverse events was not reported.

\section{Secondary outcome}

\section{Change in ulcer size}

Four studies with 191 participants contributed to the analysis of change in ulcer size (Kajagar 2012; Kaviani 2011; Landau 2011; Zhang 2013). In Kaviani 2011, the mean reduction of ulcer size was greater in the LLLT group than that in the placebo group two weeks after the beginning of treatment (47.5\% for LLLT group versus $29.4 \%$ for placebo group; MD $18.10 \%, 95 \% \mathrm{Cl} 11.16 \%$ to $25.04 \%)$ and four weeks after the beginning of treatment $(73.7 \%$ for LLLT group versus $47.3 \%$ for placebo group; MD $26.40 \%, 95 \% \mathrm{Cl} 15.91 \%$ to $36.89 \%$ ) (see Analysis 1.2); the quality of the evidence was low due to high risk of bias for incomplete outcome data and wide confidence interval. In Zhang 2013, the reduction of the ulcer size one week after treatment was $10.8 \%$ in the phototherapy group compared with $11.3 \%$ in control group (MD $0.50 \%, 95 \% \mathrm{Cl}-0.74 \%$ to $1.74 \%$ ) (see Analysis 1.2); the quality of the evidence was low due to unclear risk of bias in the original trial and small sample size. The phototherapy group had greater mean reduction in ulcer size two weeks after treatment (23.8\% for LLLT group versus $21.9 \%$ for placebo group; MD $1.90 \%, 95 \% \mathrm{Cl} 0.10 \%$ to $3.70 \%$ ) and three weeks after treatment $(41.7 \%$ for LLLT group versus $38.1 \%$ for placebo group; MD $3.60,95 \% \mathrm{Cl} 0.19$ to 7.01 ) (see Analysis 1.2); the quality of the evidence was low due to unclear risk of bias in the original trial and small sample size. In Landau 2011, the Mann-Whitney U 
test reported by the authors suggested that the mean reduction in wound size for the treatment group was greater than that for the placebo group (89\% versus 54\%; reported $P=0.048$ ). In Kajagar 2012, the mean reduction in ulcer area after the completion of 15 days of therapy tended to be larger in the phototherapy group than in the control group $\left(1043.20 \mathrm{~mm}^{2}\right.$ for the phototherapy group versus $322.44 \mathrm{~mm}^{2}$ for the control group; MD $720.76 \mathrm{~mm}^{2}, 95 \% \mathrm{Cl}$ $626.61 \mathrm{~mm}^{2}$ to $814.91 \mathrm{~mm}^{2}$ ) (see Analysis 1.3 ); the quality of the evidence was low due to unclear risk of bias in the original trial and small sample size. We did not combine these studies because i) different measure terms were used (relative term in Kaviani 2011, Zhang 2013, and Landau 2011, and absolute term in Kajagar 2012); ii) the standard deviation was not reported in Landau 2011; and iii) we identified major statistical heterogeneity.

\section{Quality of life}

Ortíz 2014 evaluated quality of life with the EQ visual analogue scale (EQ VAS) of the EQ-5D. The median (interquartile range) EQ VAS at study end was 80 (44) for the phototherapy group, 80 (29.5) for the high-voltage pulsed current group, and 90 (39.5) for the control group. We did not perform a test for the difference in quality of life between the phototherapy group and the control group due to insufficient data. The analysis of covariance (ANCOVA) test reported in the original study did not demonstrate clear differences between these three groups (reported $\mathrm{P}=0.18$ ).

\section{Number and level of amputations at study end}

In Kaviani 2011, two participants from the placebo group needed to be hospitalised and amputated due to extended gangrene, while no participants from the phototherapy group received amputation (RR $0.16,95 \% \mathrm{Cl} 0.01$ to 2.95 ) (see Analysis 1.4); the quality of the evidence was low due to high risk of bias for incomplete outcome data and wide confidence interval. The level of amputation in these two participants was not reported.

\section{Comparison 2. Phototherapy compared with high-voltage pulsed current}

In Ortíz 2014, nine participants treated with phototherapy were compared with 10 participants treated with high-voltage pulsed current. During the 16 weeks of intervention, wounds were completely healed in 7 of the 9 participants in the phototherapy group and in 8 of the 10 participants in the high-voltage pulsed current group (RR $0.97,95 \% \mathrm{Cl} 0.61$ to 1.55 ) (see Analysis 2.1); the quality of the evidence was low due to study limitation and imprecision. Ortíz 2014 evaluated quality of life with the EQ VAS. The median (interquartile range) EQ VAS at study end was 80 (44) for the phototherapy group and 80 (29.5) for the high-voltage pulsed current group. A test for the difference in quality of life between these groups was not performed.

\section{Sensitivity analysis}

We performed a sensitivity analysis according to study quality on phototherapy versus no phototherapy/placebo for the proportion of wounds completely healed during follow-up. We removed three out of the four studies included in the overall analysis (Kaviani 2011; Landau 2011; Ortíz 2014); the RR of the remaining study was 1.78 (95\% Cl 0.94 to 3.37 ) (Zhang 2012), suggesting that there was no major influence on the results of the primary analysis, though the precision of the estimated effect was reduced due to small sample size.

\section{DISCUSSION}

\section{Summary of main results}

This systematic review included a total of eight RCTs evaluating the effectiveness of phototherapy for the treatment of foot ulcers in people with diabetes (Summary of findings for the main comparison) (Kajagar 2012; Kaviani 2011; Landau 2011; Londahl 2013; Ortíz 2014; Zhang 2012; Zhang 2013; Zhao 2005). The quality of the evidence for study outcomes was generally low. We did not find any studies reporting valid data on the time to complete wound healing. Pooled data from four RCTs (Kaviani 2011; Landau 2011; Ortíz 2014; Zhang 2012) found that more people may have a healed wound during follow-up in the phototherapy group compared with the no phototherapy/placebo group (low quality evidence); the result was stable in sensitivity analysis by removing studies with high risk of bias. Our review found no current evidence that the number of adverse events differed between the phototherapy group and the no phototherapy/placebo group, however adverse events were mentioned in only two studies (Landau 2011; Londahl 2013), and the exact number of adverse events was not reported in Londahl 2013 so this current information is very limited.

We found four studies reporting change in ulcer size (Kajagar 2012; Kaviani 2011; Landau 2011; Zhang 2013). Though the original data were not suitable for pooling, results from individual trials generally suggested that, after two to four weeks of treatment, phototherapy may be associated with a greater reduction in ulcer size in both relative and absolute terms (low quality evidence). We found one study that reported the number of amputations at study end (Kaviani 2011), which indicated that there was no clear evidence of a difference in risk of amputations than with placebo. The difference in quality of life between the phototherapy group and the control group was unclear (Ortíz 2014).

We only found one study that compared phototherapy with another ulcer treatment device (high-voltage pulsed current) (Ortíz 2014). The results suggested that there was no clear difference in ulcer healing rate between these two treatment methods. The difference in quality of life was unclear between the two groups.

\section{Overall completeness and applicability of evidence}

The participants in the original trials included inpatients, in Zhang 2012, Zhang 2013, and Zhao 2005, and outpatients, in Kaviani 2011, Landau 2011, and Ortíz 2014. The included studies were performed in Asia (Kajagar 2012; Kaviani 2011; Landau 2011; Zhang 2012; Zhang 2013; Zhao 2005), Sweden (Londahl 2013), and Colombia (Ortíz 2014), and the main ethnicity of participants was Asians, in Kajagar 2012, Zhang 2012, Zhang 2013, and Zhao 2005, and Caucasians, in Kaviani 2011, Landau 2011, and Londahl 2013. We identified no study primarily undertaken in other ethnic groups. Most of the included participants were diagnosed with MeggittWagner grade I to II foot ulcers (Kajagar 2012; Kaviani 2011; Landau 2011; Londahl 2013; Ortíz 2014).

All of the included studies compared phototherapy with no phototherapy/placebo. Only one study compared phototherapy with other physical therapy modalities (high-voltage pulsed current) (Ortíz 2014), so the effectiveness of phototherapy compared with other types of physical therapies for treating foot ulcers in people with diabetes, such as shockwave therapy, remains unclear. The phototherapies used in the included trials included 
visible red light (Kaviani 2011; Ortíz 2014; Zhang 2012; Zhang 2013), visible red and near-infrared light (Londahl 2013), visible light (Landau 2011), and combination of far-infrared light and ultraviolet light (Zhao 2005). None of the included studies compared different forms of phototherapy or phototherapy of different output power, wavelength, power density, or dosage range.

In terms of study outcomes, all outcomes of interests in our protocol were reported. However, data for time to complete wound healing may not be valid, and data for adverse events, quality of life, and number and level of amputations at study end were sparsely reported, thus we were unable to obtain a reliable evaluation of these outcomes.

\section{Quality of the evidence}

The quality of the evidence was generally low due to bias in the included studies and imprecision of the estimated effects. Some studies did not clearly report detailed methods for randomisation, allocation concealment, and blinding. We also assessed some included studies as at high risk of bias for incomplete outcome data (Kaviani 2011; and Landau 2011), and imbalanced baseline characteristics (Ortíz 2014). In addition, the sample sizes of the included studies were small; the participant numbers in five out of the eight included studies were less than 30 .

\section{Potential biases in the review process}

Though we did not limit the language in searching and searched both of the main English and Chinese databases, we might have missed potentially eligible studies that were published in other languages. However, as English is the dominant language in research, the potential influence would be minor. In addition, the full texts of two potentially eligible studies were not available, and some information, such as the detailed study methodology, were not reported by the authors. Attempts to obtain these missing data, such as by contacting study authors by email, were generally unsuccessful. Lastly, the results were likely to be influenced by factors such as ulcer aetiology, however the potential influence was unclear as most included studies did not report this information.

\section{Agreements and disagreements with other studies or reviews}

Our results were consistent with the study undertaken by Minatel and colleagues (Minatel 2009), which compared phototherapy with placebo for diabetic patients with leg ulcers. We excluded this study because not all the leg ulcers in this study were foot ulcers. The mean ulcer granulation and healing rates were higher for the phototherapy group than the placebo group throughout the study period. By day $90,58.3 \%$ of ulcers in the phototherapy group had fully healed, compared with $10 \%$ in the placebo group. In Schindl 1998, Saied 2011, and Schindl 2002, phototherapy was shown to be effective in improving skin circulation in people with diabetic microangiopathy, supporting a beneficial effect of phototherapy.
In addition to clinical trials, systematic reviews have been performed to evaluate multiple interventions for chronic ulcers of the foot in diabetes, and phototherapy is one of the interventions to have been evaluated (Beckmann 2014; Game 2012; Kwan 2013). These studies summarised the results from original trials only in a narrative manner, generally suggesting that only a few studies were conducted on phototherapy; however, positive findings were reported and further large RCTs to confirm their results were encouraged.

\section{AUTHORS' CONCLUSIONS}

\section{Implications for practice}

This systematic review of randomised trials suggests that phototherapy (wavelength: $253.7 \mathrm{~nm}$ to $9.6 \mu \mathrm{m}$; dose: 2 to 10 $\mathrm{J} / \mathrm{cm}^{2}$; treatment frequency: twice daily to twice per week), when compared to no phototherapy/placebo, may increase the proportion of wounds completely healed during follow-up (followup time: 4 to 20 weeks) and reduce wound size (follow-up time: 2 to 4 weeks) in people with diabetes, but there was no clear evidence that the quality of life was different between the phototherapy group and the control group. There was a paucity of information for other outcomes, such as time to complete wound healing, adverse events, and lower limb amputation. Comparisons between phototherapy and other physical therapy modalities are also lacking. Due to small sample size and methodological flaws in the original trials, it remains unclear whether phototherapy could be an effective option for the treatment of foot ulcers in people with diabetes.

\section{Implications for research}

Given the small sample size and methodological flaws in the original trials, there is a need for large, well-designed randomised controlled trials to confirm the beneficial effect of phototherapy on foot ulcers in people with diabetes. In addition, future trials should report clinical outcomes such as quality of life and time to wound healing. Though the incidence maybe low, future studies should endeavour to fully report treatment-related adverse events and lower limb amputations so that study data may ultimately be aggregated to evaluate the risk for these important endpoints. Moreover, as data on comparisons between phototherapy and other types of physical therapies were very limited, clinical trials and secondary studies such as indirect comparison and network meta-analysis may generate useful evidence for decision making.

\section{ACK N OWLEDGEMENTS}

The review authors would like to thank peer referees Susan O'Meara, Zipporah Iheozor-Ejiofor, Gill Worthy, Nicolette Houreld and Brian Stafford for their comments on the review. Thanks are also due to peer referees Andrea Nelson, Caroline Main, Lukas Schmuelling, Odie Geiger and Jane Nadel who provided feedback on the protocol. The authors are grateful to copy editor Lisa Winer for her comments and assistance with this review. 


\section{REFERE N CES}

\section{References to studies included in this review}

Kajagar 2012 \{published data only\}

Kajagar BM, Godhi AS, Pandit A, Khatri S. Efficacy of low level laser therapy on wound healing in patients with chronic diabetic foot ulcers: a randomised control trial. Indian Journal of Surgery 2012;74(5):359-63.

\section{Kaviani 2011 \{published data only\}}

Kaviani A, Djavid GE, Ataie-Fashtami L, Fateh M, Ghodsi M, Salami M, et al. A randomized clinical trial on the effect of low-level laser therapy on chronic diabetic foot wound healing: a preliminary report. Photomedicine and Laser Surgery 2011;29(2):109-14.

\section{Landau 2011 \{published data only\}}

Landau Z, Migdal M, Lipovsky A, Lubart R. Visible lightinduced healing of diabetic or venous foot ulcers: a placebocontrolled double-blind study. Photomedicine and Laser Surgery 2011:29(6):399-404.

\section{Londahl 2013 \{published data only\}}

Londahl M, Sjoberg S, Apelqvist J. Monochromatic phototherapy enhances healing rate in diabetic foot ulcers. EWMA Journal 2013;13(1 Suppl 54):A70.

Ortíz 2014 \{published data only\} Ortíz MCS, Villabona EH, Lemos DMC, Castellanos R. Effects of low level laser therapy and high voltage stimulation on diabetic wound healing. Revista de la Universidad Industrial de Santander. Salud 2013;46(2):107-17.

\section{Zhang 2012 \{published data only\}}

Zhang B, Wang Q, Li Z, He XN. Curative effect of red light irradiation treatment for diabetic foot ulcer [红光照射治疗 糖尿病足溃疡的疗效观察]. Medical Journal of West China 2012;24(10):1893-4

\section{Zhang 2013 \{published data only\}}

Zhang GP, Wang YP, Wang YH. A clinical study of red light phototherapy for the treatment of diabetic foot ulcer [红光治疗 糖尿病足临床研究]. China Practical Medicine 2013;8(21):54-5.

\section{Zhao 2005 \{published data only\}}

Zhao DL, Zhang CN, Zhang XY, Yang XY, Zhao L. Phototherapy for the treatment of diabetic foot ulcers [光疗法治疗糖尿 病足的疗效观察]. Chinese Journal of Physical Medicine and Rehabilitation 2005;27(10):589-90.

\section{References to studies excluded from this review}

\section{Chi 2002 \{published data only\}}

Chi LY, Huang JQ, Li JH, Teng YP, Xue YS, Zhang Q. Laser therapy for the treatment of diabetic foot ulcers [激光外照射治疗糖尿 病足溃疡]. Hainan Medical Journal 2002;13(8):21-2.

\section{Hart 2004 \{published data only\}}

Hart GC, Vowden K, Gregson J, Cameron RG, Lovatt A. Study of the therapeutic effects of continuous pulsed laser light on wound rates. 2nd World Union of Wound Healing Societies Meeting; 2004 July 8-13; Paris, France. 2004:86.

ISRCTN21741608 \{unpublished data only\} ISRCTN21741608. Randomised controlled trial of the effectiveness of low level laser therapy given by District Nurses in the treatment of chronic wounds and ulcers on the lower leg. www.isrctn.com/ISRCTN21741608 (first received 30 September 2005).

Minatel 2009 \{published data only\}

Minatel DG, Frade MAC, França SC, Enwemeka CS. Phototherapy promotes healing of chronic diabetic leg ulcers that failed to respond to other therapies. Lasers in Surgery and Medicine 2009;41(6):433-41.

Minatel 2010 \{published data only\}

Minatel DG, Leite SN, Enwemaka CS, Frade MAC, França SC. Phototherapy associated sulphadiazine or phytotherapy cream for treatment of the leg ulcers in diabetic patients. Symposium on Advanced Wound Care; 2010 April 17-20; Orlando, Florida. 2010:S33

Nawfar 2011 \{published data only\}

Nawfar SA, Yacob NBM. Effects of monochromatic infrared energy therapy on diabetic feet with peripheral sensory neuropathy: a randomised controlled trial. Singapore Medical Journal 2011;52(9):669-72.

Rinaldi 1993 \{published data only\} Rinaldi F, Alberetto M, Pontiroli AE, Pozza G. Efficacy of $\mathrm{CO}_{2}$ laser beam in the management of diabetic leg ulcers. European Journal of Plastic Surgery 1993;23(Suppl):A9.

Saied 2011 \{published data only\}

Saied GM, Kamel RM, Labib AM, Said MT, Mohamed AZ. The diabetic foot and leg: combined He-Ne and infrared lowintensity lasers improve skin blood perfusion and prevent potential complications. A prospective study on 30 Egyptian patients. Lasers in Medical Science 2011;26(5):627-32.

\section{Schindl 1998 \{published data only\}}

Schindl A, Schindl M, Schön H, Knobler R, Havelec L, Schindl L. Low-intensity laser irradiation improves skin circulation in patients with diabetic microangiopathy. Diabetes Care 1998;21(4):580-4.

Schindl 2002 \{published data only\}

Schindl A, Heinze G, Schindl M, Pernerstorfer-Schön H, Schindl L. Systemic effects of low-intensity laser irradiation on skin microcirculation in patients with diabetic microangiopathy. Microvascular Research 2002;64(2):240-6.

\section{References to studies awaiting assessment}

Jones 2002 \{published data only\}

Jones R, Gorvett T, Brenton K, Price D, Chung W. A study examining the efficacy of low intensity laser therapy (LILT) in the 
management of diabetic foot ulcers. Diabetic Foot Study Group Meeting; 29 Aug - 1 Sep 2002; Budapest, Hungary. 2002:10.

\section{References to ongoing studies}

NCT02452086 \{unpublished data only\}

NCT02452086. Low level laser therapy and expression of VEGF, NO, VEGFR-2, HIF-1a in diabetic foot ulcers. clinicaltrials.gov/ ct2/show/NCT02452086 (first received 10 May 2015).

\section{NCT02677779 \{unpublished data only\}}

NCT02677779. $\mathrm{CO}_{2}$-laser treatment in patients with diabetic infected foot ulcers (DULCIS). clinicaltrials.gov/ct2/show/ NCT02677779 (first received 3 February 2016).

\section{Additional references}

\section{Apelqvist 2000a}

Apelqvist J, Bakker K, van Houtum WH, Nabuurs-Franssen MH, Schaper NC, International Working Group on the Diabetic Foot. International consensus and practical guidelines on the management and the prevention of the diabetic foot. Diabetes/ Metabolism Research and Reviews 2000;16(Suppl 1):84-92.

\section{Apelqvist 2000b}

Apelqvist J, Larsson J. What is the most effective way to reduce incidence of amputation in the diabetic foot?. Diabetes/ Metabolism Research and Reviews 2000;16(Suppl 1):75-83.

\section{Barr 2007}

Barr EL, Zimmet PZ, Welborn TA, Jolley D, Magliano DJ, Dunstan DW, et al. Risk of cardiovascular and all-cause mortality in individuals with diabetes mellitus, impaired fasting glucose, and impaired glucose tolerance: the Australian Diabetes, Obesity, and Lifestyle Study (AusDiab). Circulation 2007;116(2):151-7.

\section{Basford 1989}

Basford JR. Low-energy laser therapy: controversies and new research findings. Lasers in Surgery and Medicine 1989;9(1):1-5.

\section{Beckmann 2014}

Beckmann KH, Meyer-Hamme G, Schröder S. Low level laser therapy for the treatment of diabetic foot ulcers: a critical survey. Evidence-Based Complementary and Alternative Medicine 2014;2014:626127.

\section{Boulton 2000}

Boulton A. The pathway to ulceration: aetiopathogenesis. In: Boulton A, Connor H, Cavanagh PR editor(s). The Foot in Diabetes. 3rd Edition. Chichester: John Wiley \& Sons Ltd, 2000:19-31.

\section{Boulton 2008}

Boulton AJ, Armstrong DG, Albert SF, Frykberg RG, Hellman R, Kirkman MS. Comprehensive foot examination and risk assessment: a report of the Task Force of the Foot Care Interest Group of the American Diabetes Association, with endorsement by the American Association of Clinical Endocrinologists. Diabetes Care 2008;31(8):1679-85.

\section{CDC 2014}

Centers for Disease Control and Prevention (CDC). National diabetes statistics report, 2014. www.cdc.gov/diabetes/pubs/ statsreport14/national-diabetes-report-web.pdf (accessed 27 May 2016).

\section{Chen 2008}

Chen $\mathrm{CH}$, Hung HS, Hsu SH. Low-energy laser irradiation increases endothelial cell proliferation, migration, and eNOS gene expression possibly via PI3K signal pathway. Lasers in Surgery and Medicine 2008;40(1):46-54.

\section{Cury 2013}

Cury V, Moretti Al, Assis L, Bossini P, de Souza Crusca J, Neto CB. Low level laser therapy increases angiogenesis in a model of ischemic skin flap in rats mediated by VEGF, HIF-1alpha and MMP-2. Journal of Photochemistry and Photobiology B: Biology 2013;125:164-70.

\section{Dourado 2011}

Dourado DM, Favero S, Matias R, Carvalho PdTC, da CruzHofling MA. Low-level laser therapy promotes vascular endothelial growth factor receptor-1 expression in endothelial and nonendothelial cells of mice gastrocnemius exposed to snake venom. Photochemistry and Photobiology 2011;87(2):418-26.

\section{Egger 1997}

Egger M, Davey Smith G, Schneider M, Minder C. Bias in meta-analysis detected by a simple, graphical test. $B M J$ 1997;315(7109):629-34.

\section{El-Deen 2014}

El-Deen HB, Fahmy S, Ali SA, El-Sayed WM. Polarized light versus light-emitting diode on healing of chronic diabetic foot ulcer. Romanian Journal of Biophysics 2014;24(2):1-15.

\section{Ellen 2007}

Ellen LA, Brett MK. Diabetes, the metabolic syndrome, and ischemic stroke: epidemiology and possible mechanisms. Diabetes Care 2007;30(12):3131-40.

\section{Fung 2002}

Fung DT, Ng GY, Leung MC, Tay DK. Therapeutic low energy laser improves the mechanical strength of repairing medial collateral ligament. Lasers in Surgery and Medicine 2002;31(2):91-6.

\section{Game 2012}

Game FL, Hinchliffe RJ, Apelqvist J, Armstrong DG, Bakker K, Hartemann A, et al. A systematic review of interventions to enhance the healing of chronic ulcers of the foot in diabetes. Diabetes/Metabolism Research and Reviews 2012;28(Suppl 1):119-41.

\section{Gorshkova 2013}

Gorshkova OP, Shuvaeva VN, Dvoretsky DP. Role of nitric oxide in responses of pial arterial vessels to low-intensity red laser irradiation. Bulletin of Experimental Biology and Medicine 2013;155(5):598-600. 


\section{Guyatt 2008a}

Guyatt G, Oxman A, Vist G, Kunz R, Falck-Ytter Y, Schunemann H. GRADE: what is 'quality of evidence' and why is it important to clinicians?. BMJ 2008;336(7651):995-8.

\section{Guyatt 2008b}

Guyatt G, Oxman A, Vist G, Kunz R, Falck-Ytter Y, Alonso-Coello P. GRADE: an emerging consensus on rating quality of evidence and strength of recommendations. BMJ 2008;336(7650):924-6.

\section{Higgins 2003}

Higgins JP, Thompson SG, Deeks JJ, Altman DG. Measuring inconsistency in meta-analyses. BMJ 2003;327(7414):557-60.

\section{Higgins 2011a}

Higgins JP, Green S, editor(s). Cochrane Handbook for Systematic Reviews of Interventions Version 5.1.0 (updated March 2011). The Cochrane Collaboration, 2011. Available from handbook.cochrane.org.

\section{Higgins 2011b}

Higgins JP, Altman DG, Gøtzsche PC, Jüni P, Moher D, Oxman AD, et al. The Cochrane Collaboration's tool for assessing risk of bias in randomised trials. BMJ 2011;343:d5928.

\section{Kana 1981}

Kana JS, Hutschenreiter G, Haina D, Waidelich W. Effect of lowpower density laser-radiation on healing of open skin wounds in rats. Archives of Surgery 1981;116(3):293-6.

\section{Karu 1989}

Karu T. Photobiology of low-power laser effects. Health Physics 1989;56(5):691-704.

\section{Karu 2004}

Karu TI, Pyatibrat LV, Afanasyeva NI. A novel mitochondrial signalling pathway activated by visible-to-near infrared radiation. Photochemistry and Photobiology 2004;80(2):366-72.

\section{Khanolkar 2008}

Khanolkar MP, Bain SC, Stephens JW. The diabetic foot. Quarterly Journal of Medicine 2008;101(9):685-95.

\section{Kreisler 2002}

Kreisler M, Christoffers AB, Al-Haj H, Willershausen B, d'Hoedt B. Low level 809-nm diode laser-induced in vitro stimulation of the proliferation of human gingival fibroblasts. Lasers in Surgery and Medicine 2002;30(5):365-9.

\section{Kwan 2013}

Kwan RL, Cheing GL, Vong SK, Lo SK. Electrophysical therapy for managing diabetic foot ulcers: a systematic review. International Wound Journal 2013;10(2):121-31.

\section{Lefebvre 2011}

Lefebvre C, Manheimer E, Glanville J. Chapter 6: Searching for studies. In: Higgins JP, Green S, editor(s). Cochrane Handbook for Systematic Reviews of Interventions Version 5.1.0 (updated March 2011). The Cochrane Collaboration, 2011. Available from handbook.cochrane.org.

\section{Liberati 2009}

Liberati A, Altman DG, Tetzlaff J, Mulrow C, Gotzsche PC, loannidis JP, et al. The PRISMA statement for reporting systematic reviews and meta-analyses of studies that evaluate health care interventions: explanation and elaboration. PLOS Medicine 2009;6(7):e1000100.

\section{Lipsky 2012}

Lipsky BA, Berendt AR, Cornia PB, Pile JC, Peters EJ, Armstrong DG, et al. 2012 Infectious Diseases Society of America clinical practice guideline for the diagnosis and treatment of diabetic foot infections. Clinical Infectious Diseases 2012;54(12):e132.

\section{Lubart 1992}

Lubart R, Wollman Y, Friedmann H, Rochkind S, Laulicht I. Effects of visible and near-infrared lasers on cell cultures. Journal of Photochemistry and Photobiology B: Biology 1992;12(3):305-10.

\section{Margolis 2011}

Margolis DJ, Malay DS, Hoffstad OJ, Leonard CE, MaCurdy T, Nava KL, et al. Prevalence of diabetes, diabetic foot ulcer, and lower extremity amputation among Medicare beneficiaries, 2006 to 2008: data points \#1. Data points publication series. February 2011. www.ncbi.nlm.nih.gov/books/NBK63602/ (accessed 27 May 2016).

\section{Mathers 2006}

Mathers CD, Loncar D. Projections of global mortality and burden of disease from 2002 to 2030. PLoS Medicine 2006;3(11):e442.

\section{MedX Health 2012}

MedX Health. MedX phototherapy. www.holisticshop.ca/files/ medxbrochure.pdf (accessed 10 July 2015).

\section{MedX Health 2015}

MedX Health. About phototherapy. www.medxhealth.com/OurProducts/Phototherapy/overview.aspx (accessed 27 May 2016).

\section{Morris 1998}

Morris AD, McAlpine R, Steinke D, Boyle DIR, Ebrahim AR, Vasudev N. Diabetes and lower-limb amputations in the community: a retrospective cohort study. Diabetes Care 1998;21(5):738-43.

\section{Pereira 2002}

Pereira AN, Eduardo CP, Matson E, Marques MM. Effect of low-power laser irradiation on cell growth and procollagen synthesis of cultured fibroblasts. Lasers in Surgery and Medicine 2002;31(4):263-7.

\section{Posten 2005}

Posten W, Wrone DA, Dover JS, Arndt KA, Silapunt S, Alam M. Low-level laser therapy for wound healing: mechanism and efficacy. Dermatologic Surgery 2005;31(3):334-40. 


\section{Reiber 2001}

Reiber GE. Epidemiology of foot ulcers and amputations in the diabetic foot. In: Bowker JH, Pfeifer MA editor(s). The Diabetic Foot. St. Louis: Mosby, 2001:13-32.

\section{Rice 2014}

Rice JB, Desai U, Cummings AK, Birnbaum HG, Skornicki M, Parsons NB. Burden of diabetic foot ulcers for Medicare and private insurers. Diabetes Care 2014;37(3):651-8.

\section{Schindl 2003}

Schindl A, Merwald H, Schindl L, Kaun C, Wojta J. Direct stimulatory effect of low-intensity $670 \mathrm{~nm}$ laser irradiation on human endothelial cell proliferation. British Journal of Dermatology 2003;148(2):334-6.

\section{Shailesh 2012}

Shailesh KS, Ashok KM, Sushil KM, Surya KS, Sanjeev KG, Singh M. Prevalence of diabetic foot ulcer and associated risk factors in diabetic patients from North India. Journal of Diabetic Foot Complications 2012;4(8):83-91.

\section{SIGN 2017}

Scottish Intercollegiate Guidelines Network (SIGN). Search filters. www.sign.ac.uk/methodology/filters.html\#random (accessed 27 May 2017).

\section{Singh 2005}

Singh N, Armstrong DG, Lipsky BA. Preventing foot ulcers in patients with diabetes. JAMA 2005;293(2):217-28.

\section{Stockl 2004}

Stockl K, Vanderplas A, Tafesse E, Chang E. Costs of lowerextremity ulcers among patients with diabetes. Diabetes Care 2004;27(9):2129-34.

\section{Thornton 2000}

Thornton A, Lee P. Publication bias in meta-analysis: its causes and consequences. Journal of Clinical Epidemiology 2000;53(2):207-16

\section{Trautner 1996}

Trautner C, Haastert B, Giani G, Berger M. Incidence of lower limb amputations and diabetes. Diabetes Care 1996;19(9):1006-9.

\section{Trelles 1987}

Trelles MA, Mayayo E. Bone-fracture consolidates faster with low-power laser. Lasers in Surgery and Medicine 1987;7(1):36-45.

\section{CHARACTERISTICS OF STUDIES}

Characteristics of included studies [ordered by study ID]

\section{Tseng 2003}

Tseng $\mathrm{CH}$. Prevalence and risk factors of diabetic foot problems in Taiwan: a cross-sectional survey of non-type 1 diabetic patients from a nationally representative sample. Diabetes Care 2003;26(12):3351.

\section{Vargas 2005}

Vargas JT. Low-level laser acupuncture. Medical Acupuncture 2005;16(2):38-41.

\section{Verma 2012}

Verma SK, Maheshwari S, Singh RK, Chaudhari PK. Laser in dentistry: an innovative tool in modern dental practice. National Journal of Maxillofacial Surgery 2012;3(2):124-32.

\section{WHO 2014}

World Health Organization (WHO). Global Status Report on Noncommunicable Diseases 2014. www.who.int/nmh/ publications/ncd-status-report-2014/en/ (accessed 27 May 2016).

\section{Wrobel 2001}

Wrobel J, Mayfield J, Reiber G. Geographic variation of lower-extremity major amputation in individuals with and without diabetes in the Medicare population. Diabetes Care 2001;24(5):860-4.

\section{Yu 1997}

Yu W, Naim JO, McGowan M, Ippolito K, Lanzafame RJ. Photomodulation of oxidative metabolism and electron chain enzymes in rat liver mitochondria. Photochemistry and Photobiology 1997;66(6):866-71.

\section{Ziegler-Graham 2008}

Ziegler-Graham K, MacKenzie EJ, Ephraim PL, Travison TG, Brookmeyer R. Estimating the prevalence of limb loss in the United States: 2005 to 2050. Archives of Physical Medicine and Rehabilitation 2007;89(3):422-9.

\section{Zimny 2002}

Zimny S, Schatz H, Pfohl M. Determinants and estimation of healing times in diabetic foot ulcers. Journal of Diabetes and its Complications 2002;16(5):327-32.

\section{References to other published versions of this review \\ Wang 2015}

Wang HT, Yuan JQ, Zhang B, Dong ML, Mao C, Hu DH. Phototherapy for treating foot ulcers in people with diabetes. Cochrane Database of Systematic Reviews 2015, Issue 11. [DOI: 10.1002/14651858.CD011979]

Kajagar 2012 
Kajagar 2012 (Continued)

Participants
Setting: KLES Dr. Prabhakar Kore Hospital and Medical Research Centre, Belgaum.

Number: 34 in the intervention group, 34 in the control group.

Inclusion criteria: Type 2 diabetes mellitus patients with Meggitt-Wagner grade I diabetic foot ulcer of at least 4 weeks' duration.

Exclusion criteria: Patients with clinical signs of ischaemia and ankle brachial pressure index less than 0.9 .

Mean age: 50.9 years.

Male/Female: 51/17.

Average BMI: Not reported.

Ulcer duration: 4 to 5 weeks.

Ulcer size: Not reported.

Duration of diabetes: Not reported.

Peripheral neuropathy: 9 (26.47\%) participants in study group; 6 (17.64\%) participants in control group
Intervention group: LLLT + conventional therapy.

Control group: Conventional therapy.

LLLT was carried out with a multidiode cluster probe (Thor International Ltd). On the basis of the ulcer size, the duration of exposure was calculated to deliver 2 to $4 \mathrm{~J} / \mathrm{cm}^{2}$ at $60 \mathrm{~mW}, 5 \mathrm{kHz}$, daily for 15 days. The ulcer floor and edge were irradiated. The ulcer was then covered with conventional moist dressing.

Conventional treatment included daily wet saline or povidone-iodine (Betadine) dressings, antibiotic treatment, contact cast immobilisation, and slough excision as and when required.

Duration of treatment: 15 days.

Outcomes

Change in ulcer size. Ulcer area was calculated by obtaining the impression of ulcer floor on a sheet of cellophane paper and then transferring the imprint onto graph paper. The ulcer size was measured on day 0 and day 15.

Notes No funding resources and declaration of conflicts of interests were reported.

\section{Risk of bias}

\begin{tabular}{lll}
\hline Bias & Authors' judgement & Support for judgement \\
\hline $\begin{array}{l}\text { Random sequence genera- } \\
\text { tion (selection bias) }\end{array}$ & Low risk & $\begin{array}{l}\text { Quote: "Patients were randomised into two groups of 34 each on the basis of } \\
\text { computer generated numbers" }\end{array}$ \\
\hline
\end{tabular}

\begin{tabular}{lll}
\hline $\begin{array}{l}\text { Allocation concealment } \\
\text { (selection bias) }\end{array}$ & Unclear risk & Comment: No mention of how the randomisation sequence was concealed. \\
\hline $\begin{array}{l}\text { Blinding of participants } \\
\text { and personnel (perfor- } \\
\text { mance bias) }\end{array}$ & Unclear risk & $\begin{array}{l}\text { Comment: No mention of how blinding of participants and personnel was im- } \\
\text { plemented. }\end{array}$ \\
All outcomes & & \\
\hline
\end{tabular}

Blinding of outcome as- Unclear risk sessment (detection bias)
Comment: No mention of how blinding of outcome assessment was implemented. 
Kajagar 2012 (Continued)

All outcomes

$\begin{array}{ll}\begin{array}{l}\text { Incomplete outcome data } \\ \text { (attrition bias) }\end{array} & \text { Cow risk } \\ \text { All outcomes } & \text { analysis. }\end{array}$

All outcomes

\begin{tabular}{lll}
\hline $\begin{array}{l}\text { Selective reporting (re- } \\
\text { porting bias) }\end{array}$ & Unclear risk & $\begin{array}{l}\text { Comment: Insufficient information to permit judgement of low or high risk of } \\
\text { bias. }\end{array}$ \\
\hline Other bias & Unclear risk & $\begin{array}{l}\text { Comment: Insufficient information to assess whether an important risk of bias } \\
\text { exists. }\end{array}$
\end{tabular}
exists.

Kaviani 2011

Methods Randomised, double-blind, placebo-controlled trial. Follow-up time: 20 weeks.

Participants

Setting: Iranian Center for Medical Laser (ICML) clinic of the Academic Center for Education, Culture and Research (ACECR)

Number of participants: 13 in the intervention group, 10 in the control group.

Inclusion criteria: Patients with a diabetic foot ulcer for a minimum of 12 weeks with ulcer stage I and II according to the Wagner classification who were capable of giving informed consent, understanding instructions, and co-operating with study protocol completely were enrolled in this study.

Exclusion criteria: The presence of active infection requiring hospitalisation, gangrene, systemic diseases such as collagen-vascular diseases, renal failure, evidence of ischaemia, pregnancy, and history of photosensitivity.

Mean age: 60.2 year in intervention group, 59.4 in control group.

Male/Female: 12/6.

Ulcer duration: 11.4 months in intervention group, 8.8 in control group.

Ulcer size: $10.7 \mathrm{~cm}^{2}$ in intervention group, $7.8 \mathrm{~cm}^{2}$ in control group.

Interventions Intervention group: LLLT + conventional therapy.

Control group: Conventional therapy.

LLLT was performed with a laser device (BTL; $685 \mathrm{~nm}, 50 \mathrm{~mW}$ ) at a fluence of $10 \mathrm{~J} / \mathrm{cm}^{2}$ (with $200 \mathrm{sec}$ of illumination) with a special head in non-contact mode at a distance of $1 \mathrm{~cm}$ from the skin surface (irradiation area was approximately $1 \mathrm{~cm}^{2}$ ). Participants received illuminations over the ulcers 6 times per week for at least 2 successive weeks and then every other day up to complete healing.

Conventional therapy included revision of dead and infected tissue and off-loading when necessary, individualised topical treatment and dressings, and oral antibiotics when necessary.

Treatment duration: 20 weeks.

Outcomes

Primary outcome: Proportion of wounds completely healed during follow-up.

Secondary outcome: Change in ulcer size. The ulcer size was determined in square centimeters through digital imaging and tracing with engineered software. The ulcer size was measured at week 2 and week 4 . 
Kaviani 2011 (Continued)

Notes

This study was approved and granted by Endocrinology \& Metabolism Research Center (EMRC), Tehran University of Medical Sciences, Tehran, Iran. The authors declared that there were no conflicting financial interests.

\section{Risk of bias}

\begin{tabular}{lll}
\hline Bias & Authors' judgement & Support for judgement \\
\hline $\begin{array}{l}\text { Random sequence genera- } \\
\text { tion (selection bias) }\end{array}$ & Low risk & $\begin{array}{l}\text { Quote: "The randomization list was prepared by an independent statistician } \\
\text { by the method of computerized random numbers for each treatment." }\end{array}$ \\
\hline $\begin{array}{l}\text { Allocation concealment } \\
\text { (selection bias) }\end{array}$ & Unclear risk & Comment: No mention of how the randomisation sequence was concealed. \\
\hline $\begin{array}{l}\text { Blinding of participants } \\
\text { and personnel (perfor- } \\
\text { mance bias) }\end{array}$ & Low risk & $\begin{array}{l}\text { Quote: "Patients were examined by a physician blinded to treatment at base- } \\
\text { line and follow-up sessions, and demographic and clinical data were docu- } \\
\text { mented". "Patients in the placebo treatment group similarly received sham ir- } \\
\text { radiation under strictly controlled double-blinded conditions". "For the pur- } \\
\text { pose of safety, all patients were instructed to wear safety goggles. Since LLLT } \\
\text { provides no sensory cues such as thermal or acoustic effects, wearing goggles } \\
\text { blinded the patients to the procedure of LLTT at the same time" }\end{array}$
\end{tabular}

$\begin{array}{lll}\begin{array}{l}\text { Blinding of outcome as- } \\ \text { sessment (detection bias) }\end{array} & \text { Low risk } & \begin{array}{l}\text { Quote: "The image was processed by engineered software, AutoCAD 2002, by } \\ \text { two physicians blinded to treatment." }\end{array}\end{array}$

All outcomes

Incomplete outcome data High risk

(attrition bias)

All outcomes
Quote: "Of 23 patients enrolled in the study, five patients could not complete follow-up sessions till 20 weeks. Two patients from the placebo group needed to be hospitalized and amputated due to extended gangrene. One patient in the LLLT group was hospitalized for treatment of infection. One patient from each group died due to myocardial infarction."

Comment: The reasons for missing outcome data were likely to be related to the outcome.

\begin{tabular}{lll}
$\begin{array}{l}\text { Selective reporting (re- } \\
\text { porting bias) }\end{array}$ & Low risk & Comment: Published reports include all expected outcomes. \\
\hline Other bias & Unclear risk & $\begin{array}{l}\text { Comment: Insufficient information to assess whether an important risk of bias } \\
\text { exists. }\end{array}$
\end{tabular}

Landau 2011

\begin{tabular}{ll}
\hline Methods & Randomised, double-blind, placebo-controlled trial. Follow-up time: 12 weeks. \\
\hline Participants & Setting: Kaplan Medical Center, Rehovot, Israel. \\
Number of participants: 10 in the intervention group, 6 in the control group. \\
Inclusion criteria: \\
- Diabetic foot ulcer or a venous leg ulcer of at least 8 weeks' duration. \\
- Ulcers that had not improved after prior conventional medical treatments, which included debride- \\
ment, antibiotics, various ointments, and the use of elastic socks in cases of vascular dysfunction. \\
- Diabetic foot ulcers of grade 1 or 2 according to Wagner's classification. These would be superficial \\
ulcers with no subcutaneous involvement (grade 1), or deeper sores reaching the subcutaneous tissue \\
level in which the ulcer extension involves ligament, tendon, joint capsule, or fascia (grade 2).
\end{tabular}


Landau 2011 (Continued)

- Venous leg ulcer $<4 \mathrm{~cm}^{2}$.

\section{Exclusion criteria:}

- Severe infection.

- Having received antibiotic treatment during the week prior to the study.

- Severe vascular illness, characterised by an ankle brachial index of $<0.5$, being a candidate for vascular surgery, or having undergone revascularisation surgery within 10 weeks prior to the study.

- Photosensitive diseases.

- Malignancies or renal dysfunction.

- Being on immunosuppressive medications or having a creatinine level of $>2 \mathrm{mg} \%$.

- Pregnancy.

- Being on dialysis.

- Anaemia (haemoglobin of $<9 \mathrm{~g} \%$ ).

- A serum albumin level of $<3 \mathrm{mg} \%$.

- The use of becaplermin (Regranex) was forbidden during the month prior to the study, to negate possible late effects of this ointment.

- All diabetic patients were measured for diabetic neuropathy by a monofilament screening.

Mean age: 62.9 years.

Male/Female: $11 / 5$.

Average BMI: 28.5 .

Ulcer duration: Not reported.

Ulcer size: Not reported.

Duration of diabetes: Not reported.

Peripheral neuropathy: Not reported.

Interventions

Intervention group: Phototherapy + usual wound care.

Control group: Sham phototherapy (phototherapy at non-therapeutic light intensity) + usual wound care.

Phototherapy was performed with a prototype of the Vireo device $\left(180 \mathrm{~mW} / \mathrm{cm}^{2}\right.$ twice a day, wavelength: 400 to $800 \mathrm{~nm}$ ).

Usual wound care included wound cleaning, debridement, daily application of a pad of gauze soaked with saline, and wound dressing.

Treatment duration: 12 weeks.

Outcomes Proportion of wounds completely healed during follow-up, change in wound size, and adverse events. Wounds were measured once a week for 12 weeks.

\section{Notes}

The study was financed by "Qray LTD", Kiryat-Ata, Israel. The authors declared that one of the authors is the scientific advisor for Qray.

\section{Risk of bias}

\begin{tabular}{lll}
\hline Bias & Authors' judgement & Support for judgement \\
\hline $\begin{array}{l}\text { Random sequence genera- } \\
\text { tion (selection bias) }\end{array}$ & Low risk & $\begin{array}{l}\text { Quote: "The randomization of patients to treatment with the therapeutic or } \\
\text { non-therapeutic device was performed by a person who was not involved in } \\
\text { the evaluation of the study. A simple random allocation generated a number } \\
\text { for each device." }\end{array}$ \\
\hline
\end{tabular}


Landau 2011 (Continued)

Allocation concealment Unclear risk Comment: No mention of how the randomisation sequence was concealed.
(selection bias)
(selection bias)

Blinding of participants Low risk and personnel (performance bias)

All outcomes

\begin{tabular}{|c|c|c|}
\hline $\begin{array}{l}\text { Blinding of outcome as- } \\
\text { sessment (detection bias) }\end{array}$ & Unclear risk & $\begin{array}{l}\text { Comment: No mention of how blinding of outcome assessment was imple- } \\
\text { mented. }\end{array}$ \\
\hline
\end{tabular}

Quote:"The patients and the investigators were blind to the number allocation, as both the placebo and the treatment devices were identical in design and both emitted light."

\section{All outcomes}

\section{Incomplete outcome data High risk} (attrition bias)

All outcomes
Quote: "Four patients were excluded from analysis; 3 patients ( 2 from the placebo and 1 from the treatment group) were excluded because of noncompliance, as these patients did not use the device at home as instructed. One patient was excluded because of pre-existing renal failure."

Comment: The reasons for missing outcome data were likely to be related to the outcome.

\begin{tabular}{lll}
\hline $\begin{array}{l}\text { Selective reporting (re- } \\
\text { porting bias) }\end{array}$ & Low risk & Comment: Published reports include all expected outcomes. \\
\hline Other bias & Unclear risk & $\begin{array}{l}\text { Comment: Insufficient information to assess whether an important risk of bias } \\
\text { exists. }\end{array}$ \\
\hline
\end{tabular}

Londahl 2013

Methods Randomised, double-blind, placebo-controlled, multicentre trial. Follow-up time: 20 weeks.

\section{Participants}

\section{Setting: Not reported.}

Number of participants: 9 in the intervention group, 5 in the control group.

Inclusion criteria: Diabetic patients with non-ischaemic Wagner grade 1 or 2 ulcers at or below the ankle.

Exclusion criteria: Use of immunosuppressive treatment including steroids ( $>7.5 \mathrm{mg}$ prednisone/day), creatine level $>250 \mu \mathrm{g} / \mathrm{L}$, use of antibiotic treatment 2 weeks before inclusion, and $>40 \%$ ulcer area reduction during the 4-week run-in-period.

Mean age: Not reported.

Male/Female: Not reported.

Average BMI: Not reported.

Ulcer duration: 46 weeks.

Ulcer size: Not reported.

Duration of diabetes: Not reported.

Peripheral neuropathy: Not reported.

Interventions

Intervention group: Phototherapy.

Control group: Placebo treatment. 
Londahl 2013 (Continued)

Phototherapy was performed with a non-invasive, non-thermal CE-marked medical device (BioLight; wavelengths of between 637 and $956 \mathrm{~nm}$ and a pulse repetition frequency between 8 and $9900 \mathrm{~Hz}$ ).

Treatment was given 3 times a week for the first 2 weeks, and twice a week thereafter for up to 20 weeks.

\begin{tabular}{ll}
\hline Outcomes & Time to $50 \%$ ulcer area reduction, and adverse events. \\
\hline Notes & No funding resources and declaration of conflict of interests were reported.
\end{tabular}

\title{
Risk of bias
}

\begin{tabular}{|c|c|c|}
\hline Bias & Authors' judgement & Support for judgement \\
\hline $\begin{array}{l}\text { Random sequence genera- } \\
\text { tion (selection bias) }\end{array}$ & Unclear risk & $\begin{array}{l}\text { Quote: "9 patients were randomised to active and } 5 \text { to placebo treatment". } \\
\text { Comment: Randomisation method was not reported. }\end{array}$ \\
\hline $\begin{array}{l}\text { Allocation concealment } \\
\text { (selection bias) }\end{array}$ & Unclear risk & Comment: No mention of how the randomisation sequence was concealed. \\
\hline $\begin{array}{l}\text { Blinding of participants } \\
\text { and personnel (perfor- } \\
\text { mance bias) } \\
\text { All outcomes }\end{array}$ & Unclear risk & $\begin{array}{l}\text { Comment: No mention of how blinding of outcome assessment was imple- } \\
\text { mented. }\end{array}$ \\
\hline $\begin{array}{l}\text { Blinding of outcome as- } \\
\text { sessment (detection bias) } \\
\text { All outcomes }\end{array}$ & Unclear risk & $\begin{array}{l}\text { Comment: No mention of how blinding of participants and personnel was im- } \\
\text { plemented. }\end{array}$ \\
\hline $\begin{array}{l}\text { Incomplete outcome data } \\
\text { (attrition bias) } \\
\text { All outcomes }\end{array}$ & Unclear risk & $\begin{array}{l}\text { Comment: Insufficient information to assess whether an important risk of bias } \\
\text { exists. }\end{array}$ \\
\hline $\begin{array}{l}\text { Selective reporting (re- } \\
\text { porting bias) }\end{array}$ & Unclear risk & $\begin{array}{l}\text { Comment: Insufficient information to assess whether an important risk of bias } \\
\text { exists. }\end{array}$ \\
\hline Other bias & Unclear risk & $\begin{array}{l}\text { Comment: Insufficient information to assess whether an important risk of bias } \\
\text { exists. }\end{array}$ \\
\hline
\end{tabular}

Ortíz 2014

Methods Double-blind, randomised controlled trial. Follow-up time: 16 weeks.

Participants

\begin{abstract}
Setting: Not reported.
Number of participants: 9 in the LLLT group, 10 in the high-voltage pulsed current group, 9 in the control group.

Inclusion criteria: 30 to 75 years old with confirmed diagnosis of diabetes mellitus (diagnosis based on WHO criteria), with ulcers localised on the distal legs or feet, classified as category I or II according to the Wagner classification system.

Exclusion criteria: Patients with uncontrolled diabetes, local infection in the ulcer site, ulcer grades III through V (Wagner classification), lower limb amputation, and neuromuscular or musculoskeletal disease were excluded.
\end{abstract}

Mean age: 59.3 years. 
Ortíz 2014 (Continued)

Male/Female: $42 / 56$.

Average BMI: Not reported.

Ulcer duration: 16.2 months.

Ulcer size: Not reported.

Duration of diabetes: 11.2 years.

Peripheral neuropathy: Not reported.

Interventions

LLLT group: LLLT + standard wound care.

HVPC group: High-voltage pulsed current + standard wound care.

Control group: Standard wound care.

LLLT: semiconductor laser diode (DMC, Brazil) with $685 \mathrm{~nm}$ wavelength emitted $30 \mathrm{~mW}$ in continuous mode, $0.0028 \mathrm{~cm}^{2}$ beam area applied punctually at $2 \mathrm{~J} / \mathrm{cm}^{2}(0.18 \mathrm{~s})$ every centimetre along the edges of the ulcer in light contact and $1.5 \mathrm{~J} / \mathrm{cm}^{2}(0.14 \mathrm{~s})$ in the wound bed in non-contact mode, 3 times a week for 16 weeks or until the wound closed.

High-voltage pulsed current: Wounds were treated with an electrical stimulator (Intelect 340 Stim model; Chattanooga Group), which produced a twin peak pulse having the following parameters: continuous mode, sub-motor voltage level, 100 pulses per second pulse frequency, and $100 \mu$ s pulse duration. The treatment was performed at 45 min 3 times a week for 16 weeks or until the wound closed.

Standard wound care: The procedure included irrigation with physiological saline solution, selective sharp debridement of necrotic tissue, and maintaining a moist environment by applying an appropriate wound dressing. Participants were also taught diabetic foot self care and pressure off-loading in the affected foot. All participants received standard wound care 7 days a week for 16 weeks or until wound closure occurred.

Outcomes

Primary outcome: Proportion of wounds completely healed during follow-up.

Secondary outcomes: Healing proportion, measurement obtained as the percentage of baseline area. Data were evaluated at week 4 , week 8 , week 12 , and week 16.

Notes The study was funded by COLCIENCIAS. The authors declared that they have no conflict of interest with participants or entities that contributed to this study.

\section{Risk of bias}

\begin{tabular}{lll}
\hline Bias & Authors' judgement & Support for judgement \\
\hline $\begin{array}{l}\text { Random sequence genera- } \\
\text { tion (selection bias) }\end{array}$ & Unclear risk & $\begin{array}{l}\text { Quote: "The randomization process was performed according to a pre-estab- } \\
\text { lished order, using randomized blocks" } \\
\text { Comment: Unclear. }\end{array}$ \\
\hline $\begin{array}{l}\text { Allocation concealment } \\
\text { (selection bias) }\end{array}$ & Unclear risk & Comment: No mention of how the randomisation sequence was concealed. \\
\hline $\begin{array}{l}\text { Blinding of participants } \\
\text { and personnel (perfor- } \\
\text { mance bias) } \\
\begin{array}{l}\text { All outcomes } \\
\text { L }\end{array}\end{array}$ & Low risk & Comment: "the care provider, and investigator were masked." \\
\hline
\end{tabular}

Blinding of outcome as- Low risk

Quote: "evaluators were blinded regarding group assignment" sessment (detection bias) 
Ortíz 2014 (Continued)

All outcomes

Incomplete outcome data Low risk Quote: "Intention to treat analysis was applied"
(attrition bias)

All outcomes

Selective reporting (re- Low risk Comment: Published reports include all expected outcomes.
porting bias)
porting bias)

Other bias High risk

\author{
Comment: There was likely to be an imbalance in total ulcer size, and ulcer \\ duration between intervention group and control group. \\ Ulcer duration, Median (IQR): LLLT 4.1 (1.2 to 4.7); HVPC 2.9 (1.2 to 12.1); Con-
trol 12.2 (8.4 to 18.1). \\ Ulcer size, Median (IQR): LLLT 62.9 (23.1 to 172.2); HVPC 20.0 (11.7 to 131.0); \\ Control 41.6 (17.5 to 398.3). \\ The authors did not do any analyses to adjust for the potential influence.
}

\title{
Zhang 2012
}

\begin{tabular}{ll}
\hline Methods & Randomised controlled trial. Follow-up time: 4 weeks. \\
\hline Participants & Setting: The inpatients treated in the Sichuan Provincial People's Hospital, Chengdu, Sichuan, China. \\
Number of participants: 30 in the intervention group, 30 in the control group. \\
Inclusion criteria: People diagnosed with a diabetic foot ulcer. \\
Mean age: 63.5 years \\
Male/Female: $18 / 12$. \\
Average BMI: Not reported. \\
Ulcer duration: Not reported. \\
Ulcer size: 4 to 6 cm 2 \\
Duration of diabetes: Not reported. \\
Peripheral neuropathy: Not reported.
\end{tabular}

Interventions Intervention group: Phototherapy + usual care.

Control group: Usual care.

Phototherapy was performed with Carnation-66 red laser device (wavelength: $640 \pm 10 \mathrm{~nm}$ ). The treatment was performed at 10 min 2 times daily for 4 weeks.

Usual care included wound cleaning, debridement, and wound dressing.

\begin{tabular}{ll}
\hline Outcomes & Proportion of wounds completely healed during follow-up. \\
\hline Notes & No funding resources and declaration of conflicts of interests were reported. \\
\hline Risk of bias & \\
\hline Bias & Authors' judgement Support for judgement \\
\hline \hline
\end{tabular}


Zhang 2012 (Continued)
Random sequence genera- Unclear risk
Comment: Randomisation method was not reported. tion (selection bias)

Allocation concealment Unclear risk Comment: No mention of how the randomisation sequence was concealed.
(selection bias)

Blinding of participants Unclear risk
and personnel (perfor-
mance bias)
All outcomes

Comment: No mention of how blinding of participants and personnel was implemented.

\begin{tabular}{lll}
\hline $\begin{array}{l}\text { Blinding of outcome as- } \\
\text { sessment (detection bias) } \\
\text { All outcomes }\end{array}$ & Unclear risk & $\begin{array}{l}\text { Comment: No mention of how blinding of outcome assessment was imple- } \\
\text { mented. }\end{array}$ \\
\hline $\begin{array}{l}\text { Incomplete outcome data } \\
\text { (attrition bias) } \\
\text { All outcomes }\end{array}$ & Low risk & $\begin{array}{l}\text { Comment: The study randomised 30 participants to each group, and all partic- } \\
\text { ipants were included in data analysis. }\end{array}$ \\
\hline $\begin{array}{l}\text { Selective reporting (re- } \\
\text { porting bias) }\end{array}$ & Unclear risk & $\begin{array}{l}\text { Comment: Insufficient information to assess whether an important risk of bias } \\
\text { exists. }\end{array}$ \\
\hline Other bias & Unclear risk & $\begin{array}{l}\text { Comment: Insufficient information to assess whether an important risk of bias } \\
\text { exists. }\end{array}$ \\
\hline
\end{tabular}

Zhang 2013

Methods $\quad$ Randomised controlled trial. Follow-up time: 21 days.

Participants

Setting: The inpatients treated in The First Hospital of Nantong, Nantong, Henan, China.

Number of participants: 42 in the intervention group, 42 in the control group.

Inclusion criteria: Patients diagnosed with a diabetic foot ulcer, Meggitt-Wagner grade II to IV.

Exclusion criteria: Hepatic or renal insufficiency, serious malnutrition, serious arteriosclerosis.

Mean age: 57.7 years.

Male/Female: Not reported.

Average BMI: Not reported.

Ulcer duration: Not reported.

Ulcer size: $18.3 \mathrm{~cm}^{2}$.

Duration of diabetes: 18.1 years.

Peripheral neuropathy: Not reported.

Control group: Usual care.

Phototherapy was performed with Carnation-22 red laser device. The treatment was performed at 10 $\min 2$ times daily for 21 days. 
Usual care included wound cleaning, debridement, wound dressing, and standard management for diabetes.

\begin{tabular}{|c|c|c|}
\hline Outcomes & \multicolumn{2}{|c|}{ Change in ulcer area, measured at day 7,14 , and 21.} \\
\hline Notes & \multicolumn{2}{|c|}{ No funding resources and declaration of conflicts of interests were reported. } \\
\hline \multicolumn{3}{|l|}{ Risk of bias } \\
\hline Bias & Authors' judgement & Support for judgement \\
\hline $\begin{array}{l}\text { Random sequence genera- } \\
\text { tion (selection bias) }\end{array}$ & Unclear risk & Comment: Randomisation method was not reported. \\
\hline $\begin{array}{l}\text { Allocation concealment } \\
\text { (selection bias) }\end{array}$ & Unclear risk & Comment: No mention of how the randomisation sequence was concealed. \\
\hline $\begin{array}{l}\text { Blinding of participants } \\
\text { and personnel (perfor- } \\
\text { mance bias) } \\
\text { All outcomes }\end{array}$ & Unclear risk & $\begin{array}{l}\text { Comment: No mention of how blinding of participants and personnel was im- } \\
\text { plemented. }\end{array}$ \\
\hline $\begin{array}{l}\text { Blinding of outcome as- } \\
\text { sessment (detection bias) } \\
\text { All outcomes }\end{array}$ & Unclear risk & $\begin{array}{l}\text { Comment: No mention of how blinding of outcome assessment was imple- } \\
\text { mented. }\end{array}$ \\
\hline $\begin{array}{l}\text { Incomplete outcome data } \\
\text { (attrition bias) } \\
\text { All outcomes }\end{array}$ & Unclear risk & $\begin{array}{l}\text { Comment: Insufficient information to assess whether an important risk of bias } \\
\text { exists. }\end{array}$ \\
\hline $\begin{array}{l}\text { Selective reporting (re- } \\
\text { porting bias) }\end{array}$ & Unclear risk & $\begin{array}{l}\text { Comment: Insufficient information to assess whether an important risk of bias } \\
\text { exists. }\end{array}$ \\
\hline Other bias & Unclear risk & $\begin{array}{l}\text { Comment: Insufficient information to assess whether an important risk of bias } \\
\text { exists. }\end{array}$ \\
\hline
\end{tabular}

\section{Zhao 2005}

Methods Randomised controlled trial. Follow-up time: 4 weeks.

Number of participants: 12 in the intervention group, 11 in the control group.

Inclusion criteria: Patients diagnosed with a diabetic foot ulcer.

Mean age: Intervention group 66.8 years, control group 68.5 years.

Male/Female: 8/15.

Average BMI: Not reported.

Ulcer duration: 7 years.

Ulcer size: Not reported.

Duration of diabetes: Not reported. 
Zhao 2005 (Continued)

Peripheral neuropathy: Not reported.

Intervention group: Phototherapy + usual care.
Conctrol group: Usual care.
Phototherapy was performed with YS- 50 far-infrared phototherapy device and YS- 2 ultraviolet light
phototherapy device. The far-infrared phototherapy (wavelength $9.6 \mu$ m) was performed at 30 min per
day for 4 weeks. The ultraviolet light phototherapy $(253.7 \mathrm{~nm})$ was performed once daily or once every
other day.
Usual care included wound cleaning, debridement, wound dressing, and standard management for di-
abetes.
Treatment duration: 4 weeks.

\begin{tabular}{ll}
\hline Outcomes & Proportion of wounds completely healed during follow-up (4 weeks). \\
\hline Notes & No funding resources and declaration of conflicts of interests were reported.
\end{tabular}

\section{Risk of bias}

\begin{tabular}{|c|c|c|}
\hline Bias & Authors' judgement & Support for judgement \\
\hline $\begin{array}{l}\text { Random sequence genera- } \\
\text { tion (selection bias) }\end{array}$ & Unclear risk & Comment: Randomisation method was not reported. \\
\hline $\begin{array}{l}\text { Allocation concealment } \\
\text { (selection bias) }\end{array}$ & Unclear risk & Comment: No mention of how the randomisation sequence was concealed. \\
\hline $\begin{array}{l}\text { Blinding of participants } \\
\text { and personnel (perfor- } \\
\text { mance bias) } \\
\text { All outcomes }\end{array}$ & Unclear risk & $\begin{array}{l}\text { Comment: No mention of how blinding of participants and personnel was im- } \\
\text { plemented. }\end{array}$ \\
\hline $\begin{array}{l}\text { Blinding of outcome as- } \\
\text { sessment (detection bias) } \\
\text { All outcomes }\end{array}$ & Unclear risk & $\begin{array}{l}\text { Comment: No mention of how blinding of outcome assessment was imple- } \\
\text { mented. }\end{array}$ \\
\hline $\begin{array}{l}\text { Incomplete outcome data } \\
\text { (attrition bias) } \\
\text { All outcomes }\end{array}$ & Low risk & $\begin{array}{l}\text { Comment: The study randomised } 12 \text { participants to the phototherapy group } \\
\text { and } 11 \text { to the control group, all of which were included in data analysis. }\end{array}$ \\
\hline $\begin{array}{l}\text { Selective reporting (re- } \\
\text { porting bias) }\end{array}$ & Unclear risk & $\begin{array}{l}\text { Comment: Insufficient information to assess whether an important risk of bias } \\
\text { exists. }\end{array}$ \\
\hline Other bias & Unclear risk & $\begin{array}{l}\text { Comment: Insufficient information to assess whether an important risk of bias } \\
\text { exists. }\end{array}$ \\
\hline
\end{tabular}

BMI: body mass index HVPC: high-voltage pulsed current IQR: interquartile range

LLLT: low-level laser therapy

WHO: World Health Organization

Characteristics of excluded studies [ordered by study ID] 


\begin{tabular}{ll}
\hline Study & Reason for exclusion \\
\hline Chi 2002 & Not a randomised controlled trial \\
\hline Hart 2004 & Participants were not eligible (wounds) \\
\hline ISRCTN21741608 & Participants were not eligible (chronic wounds and ulcers on the lower leg) \\
\hline Minatel 2009 & Participants were not eligible (diabetic leg ulcers) \\
\hline Minatel 2010 & Intervention was not eligible (sulphadiazine or phyto therapy cream) \\
\hline Nawfar 2011 & Participants were not eligible (diabetic patients with peripheral sensory neuropathy) \\
\hline Rinaldi 1993 & Not a randomised controlled trial \\
\hline Saied 2011 & $\begin{array}{l}\text { Participants were not eligible (diabetic patients with disease-related skin lesions including dryness, } \\
\text { diabetic bullae, nail changes and alopecia, infections, pruritus, and frank eczema) }\end{array}$ \\
\hline Schindl 1998 & Participants were not eligible (diabetic ulcers or gangrenes were included) \\
\hline Schindl 2002 & Participants were not eligible (diabetic microangiopathy) \\
\hline
\end{tabular}

Characteristics of studies awaiting assessment [ordered by study ID]

Jones 2002

\begin{tabular}{ll}
\hline Methods & RCT (possible) \\
\hline Participants & Diabetic patients with foot ulcers \\
\hline Interventions & LLLT \\
\hline Outcomes & Unclear \\
\hline Notes & We judged from study title. Abstract and full text were not available \\
\hline
\end{tabular}

LLLT = Low level laser therapy

Characteristics of ongoing studies [ordered by study ID]

\section{NCT02452086}

Trial name or title Low level laser effect on improving the blood flow in diabetic foot ulcers

$\begin{array}{ll}\text { Methods RCT } & \text { R }\end{array}$

\begin{tabular}{ll}
\hline Participants & Diabetic patients with ischaemic diabetic foot ulcers (of both sexes) aged 40 to 60 years \\
\hline Interventions & $\begin{array}{l}\text { Intervention } 1: \text { In placebo group, participants will be treated with standard therapy and laser every } \\
\text { other day, for } 12 \text { sessions. }\end{array}$ \\
& $\begin{array}{l}\text { Intervention 2: In laser therapy group, participants will be treated with } \mathrm{Ga}-\mathrm{As} \text { laser, } 2 \mathrm{~J} / \mathrm{cm}^{2}, 90 \mathrm{~mW}, \\
\text { and standard therapy every other day, for } 12 \text { sessions. }\end{array}$
\end{tabular}


NCT02452086 (Continued)

- Ankle Brachial Index.

- Hypoxia-inducible factor 1-alpha (HIF-1a).

- Nitric oxide.

- Oxygen saturation of peripheral blood.

- Vascular endothelial growth factor.

- Wound surface area.

Secondary outcome:

- Assessment of physical activity and pain.

\begin{tabular}{ll}
\hline Starting date & June 2013 \\
\hline Contact information & Name: Dr Gity Torkaman \\
& Address: Physiotherapy Department, Tarbiat Modares University, Jalal Ale Ahmad Highway \\
& Tehran, Islamic Republic of Iran \\
& Email: torkamg@modares.ac.ir \\
& Affiliation: Tarbiat Modares University \\
\hline Notes & Identified from WHO International Clinical Trials Registry Platform \\
\hline
\end{tabular}

NCT02677779

\begin{tabular}{ll}
\hline Trial name or title & $\mathrm{CO}_{2}$-Laser Treatment in Patients With Diabetic Infected Foot Ulcers (DULCIS) \\
\hline Methods & $\mathrm{RCT}$ \\
\hline Participants & Diabetic patients with foot ulcers \\
\hline Interventions & $\mathrm{CO}_{2}$ laser \\
\hline
\end{tabular}

Outcomes

Primary outcome measures:

- Bacterial load

- Number of bacterial colonies in a sample collected with a swab from ulcer bed

Secondary outcome measures:

- Pain: Brief pain inventory scores.

- Fibrin: percentage of ulcer area covered by fibrin.

- Necrosis: percentage of ulcer area covered by necrotic tissue.

- Granulation: proportion of participants with at least $90 \%$ of ulcer area covered by granulation tissue.

- Bleeding: proportion of participants with bleeding necessitating haemostasis.

\begin{tabular}{ll}
\hline Starting date & January 2016 \\
\hline Contact information & Edoardo Mannucci, MD, University of Florence \\
\hline Notes & Identified from WHO International Clinical Trials Registry Platform \\
\hline
\end{tabular}

$\mathrm{RCT}$ : randomised controlled trial 
WHO: World Health Organization

\section{DATA AND ANALYSES}

\section{Comparison 1. Phototherapy versus no phototherapy/placebo}

\begin{tabular}{|c|c|c|c|c|}
\hline Outcome or subgroup title & No. of studies & $\begin{array}{l}\text { No. of partici- } \\
\text { pants }\end{array}$ & Statistical method & Effect size \\
\hline $\begin{array}{l}1 \text { Proportion of wounds complete- } \\
\text { ly healed during follow-up ( } 4 \text { to } 20 \\
\text { weeks) }\end{array}$ & 4 & 116 & Risk Ratio (IV, Fixed, 95\% CI) & $1.57[1.08,2.28]$ \\
\hline $\begin{array}{l}2 \text { Change in ulcer size in relative terms } \\
\text { (percentage change in wound area) }\end{array}$ & 2 & & $\begin{array}{l}\text { Mean Difference (IV, Fixed, } \\
95 \% \mathrm{Cl} \text { ) }\end{array}$ & $\begin{array}{l}\text { Totals not select- } \\
\text { ed }\end{array}$ \\
\hline 2.1 Treatment duration (1 week) & 1 & & $\begin{array}{l}\text { Mean Difference (IV, Fixed, } \\
95 \% \mathrm{Cl} \text { ) }\end{array}$ & $0.0[0.0,0.0]$ \\
\hline 2.2 Treatment duration ( 2 weeks) & 2 & & $\begin{array}{l}\text { Mean Difference (IV, Fixed, } \\
95 \% \mathrm{Cl} \text { ) }\end{array}$ & $0.0[0.0,0.0]$ \\
\hline 2.3 Treatment duration ( 3 weeks) & 1 & & $\begin{array}{l}\text { Mean Difference (IV, Fixed, } \\
95 \% \mathrm{Cl} \text { ) }\end{array}$ & $0.0[0.0,0.0]$ \\
\hline 2.4 Treatment duration (4 weeks) & 1 & & $\begin{array}{l}\text { Mean Difference (IV, Fixed, } \\
95 \% \mathrm{CI})\end{array}$ & $0.0[0.0,0.0]$ \\
\hline $\begin{array}{l}3 \text { Change in ulcer size in absolute } \\
\text { terms (mean change in wound area) }\end{array}$ & 1 & & $\begin{array}{l}\text { Mean Difference (IV, Fixed, } \\
95 \% \mathrm{Cl} \text { ) }\end{array}$ & Subtotals only \\
\hline 3.1 Treatment duration ( 2 weeks) & 1 & 68 & $\begin{array}{l}\text { Mean Difference (IV, Fixed, } \\
95 \% \mathrm{CI})\end{array}$ & $\begin{array}{l}720.76[626.61 \\
814.91]\end{array}$ \\
\hline $\begin{array}{l}4 \text { Number of amputations at study end } \\
\text { (20 weeks) }\end{array}$ & 1 & 23 & Risk Ratio (IV, Fixed, 95\% CI) & $0.16[0.01,2.95]$ \\
\hline
\end{tabular}

Analysis 1.1. Comparison 1 Phototherapy versus no phototherapy/placebo, Outcome 1 Proportion of wounds completely healed during follow-up (4 to 20 weeks).

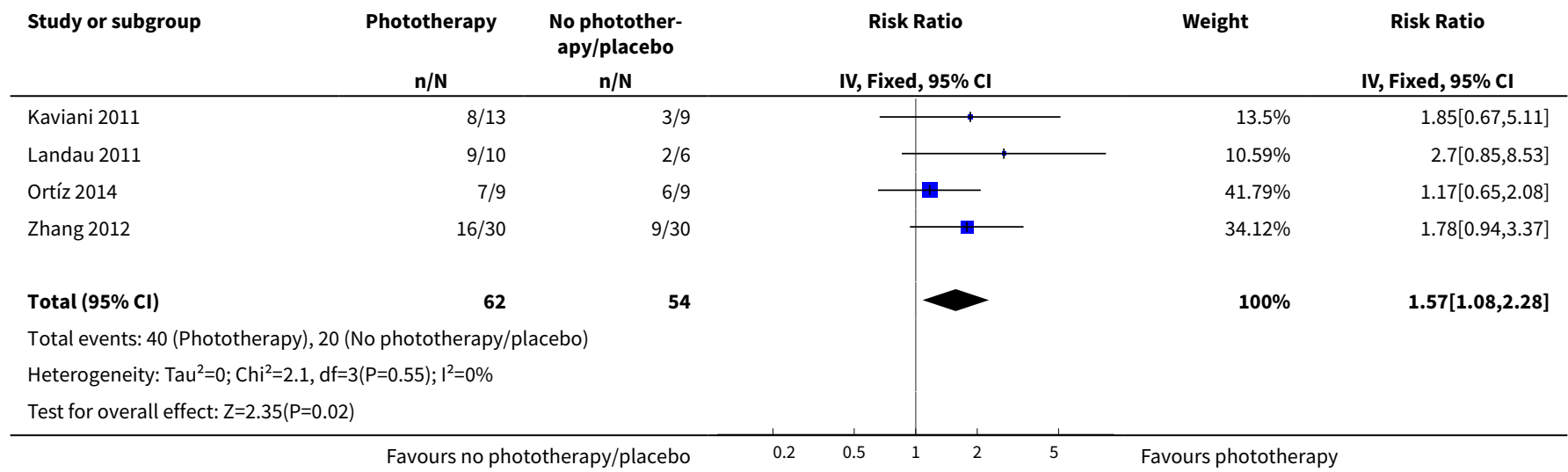


Analysis 1.2. Comparison 1 Phototherapy versus no phototherapy/placebo, Outcome $\mathbf{2}$ Change in ulcer size in relative terms (percentage change in wound area).

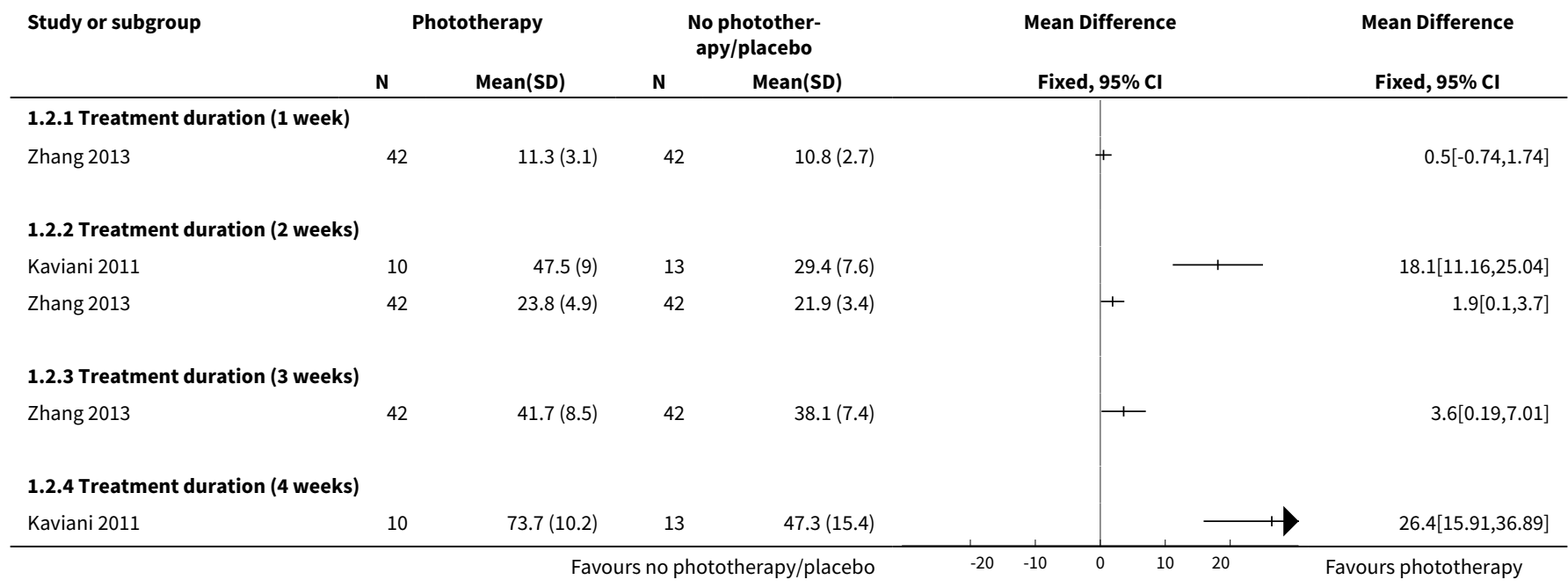

Analysis 1.3. Comparison 1 Phototherapy versus no phototherapy/placebo, Outcome 3 Change in ulcer size in absolute terms (mean change in wound area).

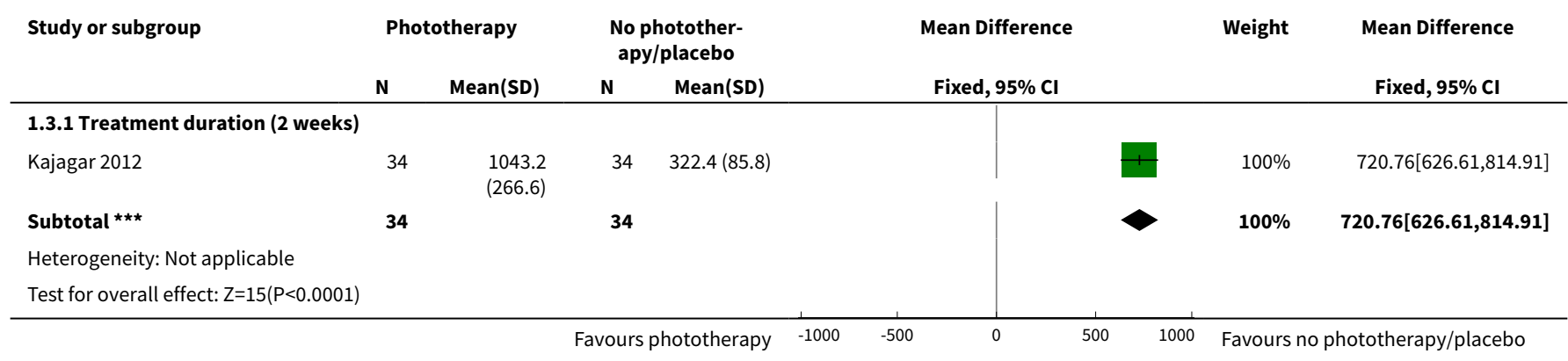

Analysis 1.4. Comparison 1 Phototherapy versus no phototherapy/ placebo, Outcome 4 Number of amputations at study end ( 20 weeks).

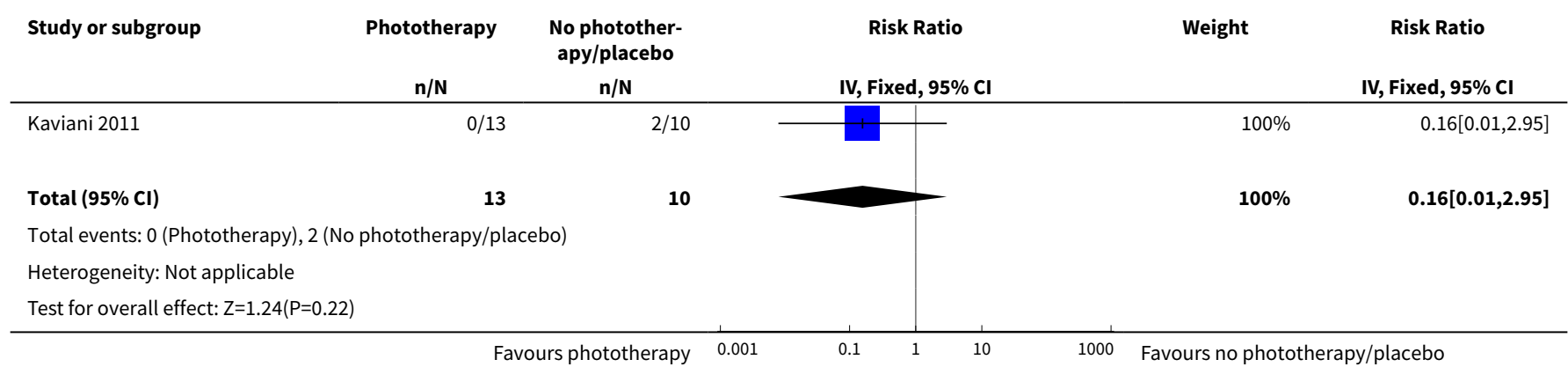




\section{Comparison 2. Phototherapy versus high-voltage pulsed current}

\begin{tabular}{lllll}
\hline Outcome or subgroup title & No. of studies & $\begin{array}{l}\text { No. of partici- } \\
\text { pants }\end{array}$ & Statistical method & Effect size \\
\hline $\begin{array}{l}\text { 1 Proportion of wounds completely healed } \\
\text { during follow-up }\end{array}$ & 1 & Risk Ratio (IV, Fixed, 95\% & $\begin{array}{l}\text { Totals not select- } \\
\text { CI) }\end{array}$ & ed \\
\hline
\end{tabular}

\section{Analysis 2.1. Comparison 2 Phototherapy versus high-voltage pulsed current, Outcome 1 Proportion of wounds completely healed during follow-up.}

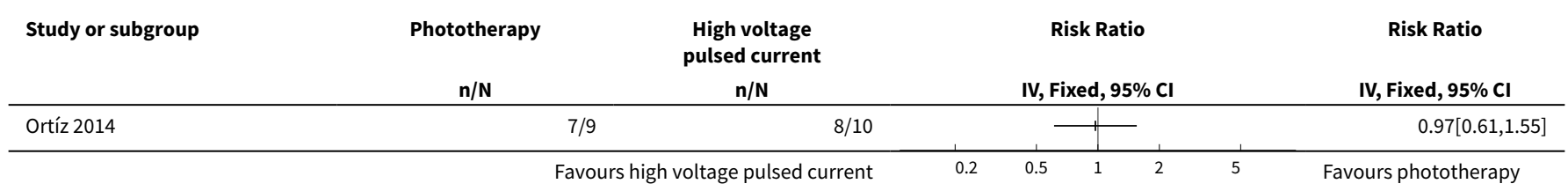

\section{APPENDICES}

\section{Appendix 1. Glossary}

Cytochrome oxidase: an oxidizing enzyme containing iron and a porphyrin, found in mitochondria and important in cell respiration as an agent of electron transfer from certain cytochrome molecules to oxygen molecules.

Mitochondria: a spherical or elongated organelle in the cytoplasm of nearly all eukaryotic cells, containing genetic material and many enzymes important for cell metabolism. Mitochondria make most of the energy for cells.

Adenosine triphosphate: a nucleotide that is the primary source of energy in all living cells because of its function in donating a phosphate group during biochemical activities.

Oxidative metabolism: the catabolic first half of metabolism in which the cell breaks down molecules into energy, or adenosine triphosphate.

Angiogenesis: the growth of blood vessels from the existing vasculature.

Vasodilation: widening of blood vessels that results from relaxation of the muscular walls of the vessels.

\section{Appendix 2. Search strategies}

\section{The Cochrane Central Register of Controlled Trials (CENTRAL)}

\#1 MeSH descriptor: [Leg Ulcer] explode all trees

\#2 MeSH descriptor: [Skin Ulcer] explode all trees

\#3 MeSH descriptor: [Foot Ulcer] explode all trees

\#4 \{or \#1-\#3\}

\#5 MeSH descriptor: [Diabetes Mellitus] explode all trees

\#6 \{and \#4-\#5\}

\#7 MeSH descriptor: [Diabetic Foot] explode all trees

\#8 \{or \#6-\#7\}

\#9 diabet*:ti,ab,kw

\#10 ((ulcer ${ }^{\star}$ or wound ${ }^{\star}$ or defect $\left.{ }^{\star}\right)$ near/3 (foot or feet or sole or plantar)):ti,ab,kw

$\# 11$ and \#9-\#10\}

\#12 (diabet ${ }^{\star}$ near/3 ulcer $\left.{ }^{\star}\right): t i, a b, k w$ (Word variations have been searched)

\#13 (diabet* near/3 (foot or feet)):ti,ab,kw (Word variations have been searched)

\#14 (diabet* near/3 wound ${ }^{\star}$ )

\#15 (diabet* ${ }^{\star}$ ear $/ 3$ defect $^{\star}$ )

\#16 \{or \#8, \#11-\#15\} 
\#17 MeSH descriptor: [Phototherapy] explode all trees

\#18 MeSH descriptor: [Laser Therapy] explode all trees

\#19 (laser ${ }^{\star}$ or ultraviolet or phototherap ${ }^{*}$ or photoradiation next therap* or photon next therap* or light next therap* or heat next therap* or LLLT or LED):ti,ab,kw (Word variations have been searched)

\#20 \{or \#17-\#19\}

$\# 21$ and \#16, \#20\} in Trials

\section{Ovid MEDLINE}

1 exp Leg Ulcer/

2 Skin Ulcer/

3 Foot Ulcer/

4 or/1-3

5 exp Diabetes Mellitus/

6 and/4-5

7 exp Diabetic Foot/

8 or/6-7

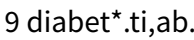

10 ((ulcer* or wound $^{\star}$ or defect $\left.{ }^{\star}\right)$ adj3 (foot or feet or sole or plantar)).ti,ab.

11 and $/ 9-10$

12 (diabet* adj3 ulcer ${ }^{\star}$ ).tw.

13 (diabet* ${ }^{\star}$ adj3 (foot or feet)).tw.

14 (diabet* $^{\star}$ adj3 wound $^{\star}$ ).tw.

15 (diabet $^{\star}$ adj3 defect $\left.{ }^{\star}\right)$.tw.

16 or/8,11-15

17 exp Phototherapy/

18 exp Laser Therapy/

19 (laser* or ultraviolet or phototherap* or photoradiation therap* or photon therap* or light therap* or heat therap* or LLLT or LED).tw.

20 or/17-19

21 and $/ 16,20$

22 randomized controlled trial.pt.

23 controlled clinical trial.pt.

24 randomi?ed.ab.

25 placebo.ab.

26 clinical trials as topic.sh.

27 randomly.ab.

28 trial.ti.

29 or $/ 22-28$

30 exp animals/not humans.sh.

3129 not 30

3221 and 31

\section{Ovid Embase}

1 exp leg ulcer/

2 skin ulcer/

3 foot ulcer/

4 plantar ulcer/

5 or/1-4

6 exp diabetes mellitus/

7 and $/ 5-6$

8 diabetic foot/

9 or/7-8

10 diabet $^{\star} . \mathrm{ti}, \mathrm{ab}$.

11 ((ulcer* or wound $^{\star}$ or defect* $\left.{ }^{\star}\right)$ adj3 (foot or feet or sole or plantar)).ti,ab.

12 and $/ 10-11$

13 (diabet ${ }^{\star}$ adj3 ulcer ${ }^{\star}$ ).tw.

14 (diabet* adj3 (foot or feet)).tw.

15 (diabet* adj3 wound*).tw.

16 (diabet ${ }^{\star}$ adj3 defect ${ }^{\star}$ ).tw.

17 or/9,12-16

18 exp phototherapy/

19 low level laser therapy/

Phototherapy for treating foot ulcers in people with diabetes (Review) 
20 (laser ${ }^{\star}$ or ultraviolet or phototherap* or photoradiation therap* or photon therap* or light therap ${ }^{\star}$ or heat therap* or LLLT or LED).tw. 21 or/ $18-20$

22 and $/ 17,21$

23 Randomized controlled trials/

24 Single-Blind Method/

25 Double-Blind Method/

26 Crossover Procedure/

27 (random $^{\star}$ or factorial ${ }^{\star}$ or crossover ${ }^{\star}$ or cross over $^{\star}$ or cross-over $^{\star}$ or placebo ${ }^{\star}$ or assign ${ }^{\star}$ or allocat ${ }^{\star}$ or volunteer $\left.{ }^{\star}\right)$.ti,ab.

28 (doubl $^{*}$ adj blind ${ }^{\star}$ ).ti,ab.

29 (singl ${ }^{\star}$ adj blind ${ }^{\star}$ ).ti,ab.

30 or/23-29

31 exp animals/ or exp invertebrate/ or animal experiment/ or animal model/ or animal tissue/ or animal cell/ or nonhuman/

32 human/ or human cell/

33 and $/ 31-32$

3431 not 33

3530 not 34

3622 and 35

\section{EBSCO CINAHL Plus}

S33 S20 AND S32

$\mathrm{S} 32 \mathrm{~S} 21$ or S22 or S23 or S24 or S25 or S26 or S27 or S28 or S29 or S30 or S31

S31 MH "Quantitative Studies"

S30 TI placebo* or AB placebo*

S29 MH "Placebos"

$\mathrm{S} 28 \mathrm{TI}$ random* ${ }^{\star}$ allocat* or AB random* allocat*

S27 MH "Random Assignment"

S26 TI randomi?ed control $^{\star}$ trial $^{\star}$ or $\mathrm{AB}$ randomi?ed control ${ }^{\star}$ trial ${ }^{*}$

S25 AB ( singl* or doubl* or trebl* or tripl ${ }^{\star}$ ) and AB ( blind ${ }^{\star}$ or mask $^{\star}$ )

S24 TI ( singl $l^{\star}$ or doubl* or trebl* or tripl ${ }^{\star}$ ) and TI ( blind ${ }^{\star}$ or mask ${ }^{\star}$ )

S23 TI clinic ${ }^{\star}$ N1 trial ${ }^{\star}$ or AB clinic* N1 trial*

S22 PT Clinical trial

S21MH "Clinical Trials+"

S20 S15 AND S19

S19 S16 OR S17 OR S18

S18 TX (laser* or ultraviolet or phototherap* or photoradiation therap* or photon therap* or light therap* or heat therap* or LLLT or LED)

S17 (MH "Laser Therapy+")

S16 (MH "Phototherapy+")

S15 S7 OR S10 OR S11 OR S12 OR S13 OR S14

S14 TX (diabet ${ }^{\star}$ N3 defect $\left.{ }^{\star}\right)$

S13 TX (diabet ${ }^{\star}$ N3 wound $\left.{ }^{\star}\right)$

S12 TX (diabet* N3 (foot or feet))

S11 TX (diabet ${ }^{\star}$ N3 ulcer $\left.^{\star}\right)$

S10 S8 AND S9

S9 TI (((ulcer ${ }^{\star}$ or wound ${ }^{\star}$ or defect $\left.{ }^{\star}\right)$ N3 (foot or feet or sole or plantar))) OR AB (((ulcer or wound $^{\star}$ or defect $\left.{ }^{\star}\right)$ N3 (foot or feet or sole or plantar)))

S8 TI (diabet $\left.{ }^{\star}\right)$ OR AB (diabet*)

S7 S5 OR S6

S6 (MH "Diabetic Foot")

S5 S3 AND S4

S4 (MH "Diabetes Mellitus+")

S3 S1 OR S2

S2 (MH "Skin Ulcer")

S1 (MH "Leg Ulcer+")

\section{CNKI}

$(A B=$ '糖尿病足 ' $O R A B=$ '糖尿病肢端坏疽 ' $O R A B=$ '糖尿病血管病变 ' $O R A B=$ '糖尿病溃疡' $O R A B=$ '烂脚 ' $O R A B=$ '烂腿 ' $O R \quad S U=$ '糖 尿病足 ' OR SU='糖尿病肢端坏瘨' $O R(A B=$ '糖尿病 ' $A N D(A B=$ '坏瘨' $O R A B=$ '足 ' $O R A B=$ '血管神经病变' $O R A B=$ '微血管病变' $O R$ $A B=$ '溃疡' $)$ ) ) $A N D(S U=$ '激光' $O R A B=$ '低强度激光' $O R A B=$ '激光 ' $O R A B=$ '红光 ' $O R A B=$ '光疗 ' $O R S U=$ '蓝光 ' $O R A B=$ '光学治疗 ') $A N D$ $(S U=$ '随机对照试验' $O R S U=$ '临床试验' $O R A B=$ '随机 'OR AB='对照' $O R A B=$ ' 盲法' $O R A B=$ '双盲 'OR $A B=$ '单盲' $O R A B=$ '随机对照试验' $O R A B=$ '临床试验' OR SU=' 多中心临床试验' ) 


\section{Terms used for searching clinical trials registries}

- Phototherapy

- LLLT

- Laser

- Light

- Diabetic Foot

- Diabetic ulcer

\section{Appendix 3. Cochrane's tool for assessing risk of bias}

\section{Was the allocation sequence randomly generated?}

\section{Low risk of bias}

The investigators describe a random component in the sequence generation process such as: referring to a random number table; using a computer random number generator; coin tossing; shuffling cards or envelopes; throwing dice; drawing of lots.

\section{High risk of bias}

The investigators describe a non-random component in the sequence generation process. Usually, the description would involve some systematic, non-random approach, for example: sequence generated by odd or even date of birth; sequence generated by some rule based on date (or day) of admission; sequence generated by some rule based on hospital or clinic record number.

\section{Unclear}

Insufficient information about the sequence generation process to permit judgement of low or high risk of bias.

\section{Was the treatment allocation adequately concealed?}

\section{Low risk of bias}

Participants and investigators enrolling participants could not foresee assignment because one of the following, or an equivalent method, was used to conceal allocation: central allocation (including telephone, web-based, and pharmacy-controlled randomisation); sequentially numbered drug containers of identical appearance; sequentially numbered, opaque, sealed envelopes.

\section{High risk of bias}

Participants or investigators enrolling participants could possibly foresee assignments and thus introduce selection bias, such as allocation based on: use of an open random allocation schedule (e.g. a list of random numbers); assignment envelopes without appropriate safeguards (e.g. envelopes were unsealed, non-opaque, or not sequentially numbered); alternation or rotation; date of birth; case record number; any other explicitly unconcealed procedure.

\section{Unclear}

Insufficient information to permit judgement of low or high risk of bias. This is usually the case if the method of concealment is not described or not described in sufficient detail to allow a definite judgement, for example if the use of assignment envelopes is described, but it remains unclear whether envelopes were sequentially numbered, opaque, and sealed.

\section{Blinding - was knowledge of the allocated interventions adequately prevented during the study?}

\section{Low risk of bias}

Any one of the following:

- No blinding, but the review authors judge that the outcome and the outcome measurement are not likely to be influenced by lack of blinding.

- Blinding of participants and key study personnel ensured, and unlikely that the blinding could have been broken.

- Either participants or some key study personnel were not blinded, but outcome assessment was blinded and the non-blinding of others unlikely to introduce bias.

\section{High risk of bias}

Any one of the following:

- No blinding or incomplete blinding, and the outcome or outcome measurement is likely to be influenced by lack of blinding.

- Blinding of key study participants and personnel attempted, but likely that the blinding could have been broken.

- Either participants or some key study personnel were not blinded, and the non-blinding of others likely to introduce bias. 


\section{Unclear}

Either of the following:

- Insufficient information to permit judgement of low or high risk of bias.

- The study did not address this outcome.

\section{Were incomplete outcome data adequately addressed?}

\section{Low risk of bias}

Any one of the following:

- No missing outcome data.

- Reasons for missing outcome data unlikely to be related to true outcome (for survival data, censoring unlikely to be introducing bias).

- Missing outcome data balanced in numbers across intervention groups, with similar reasons for missing data across groups.

- For dichotomous outcome data, the proportion of missing outcomes compared with observed event risk not enough to have a clinically relevant impact on the intervention effect estimate.

- For continuous outcome data, plausible effect size (difference in means or standardised difference in means) among missing outcomes not enough to have a clinically relevant impact on observed effect size.

- Missing data have been imputed using appropriate methods.

\section{High risk of bias}

Any one of the following:

- Reason for missing outcome data likely to be related to true outcome, with either imbalance in numbers or reasons for missing data across intervention groups.

- For dichotomous outcome data, the proportion of missing outcomes compared with observed event risk enough to induce clinically relevant bias in intervention effect estimate.

- For continuous outcome data, plausible effect size (difference in means or standardised difference in means) among missing outcomes enough to induce clinically relevant bias in observed effect size.

- 'As-treated' analysis done with substantial departure of the intervention received from that assigned at randomisation.

- Potentially inappropriate application of simple imputation.

\section{Unclear}

Either of the following:

- Insufficient reporting of attrition/exclusions to permit judgement of low or high risk of bias (e.g. number randomised not stated, no reasons for missing data provided).

- The study did not address this outcome.

\section{Are reports of the study free of suggestion of selective outcome reporting?}

\section{Low risk of bias}

Either of the following:

- The study protocol is available and all of the study's prespecified (primary and secondary) outcomes that are of interest in the review have been reported in the prespecified way.

- The study protocol is not available, but it is clear that the published reports include all expected outcomes, including those that were prespecified (convincing text of this nature may be uncommon).

\section{High risk of bias}

Any one of the following:

- Not all of the study's prespecified primary outcomes have been reported.

- One or more primary outcomes are reported using measurements, analysis methods, or subsets of the data (e.g. subscales) that were not prespecified.

- One or more reported primary outcomes were not prespecified (unless clear justification for their reporting is provided, such as an unexpected adverse effect).

- One or more outcomes of interest in the review are reported incompletely so that they cannot be entered in a meta-analysis.

- The study report fails to include results for a key outcome that would be expected to have been reported for such a study. 
Unclear

Insufficient information to permit judgement of low or high risk of bias. It is likely that the majority of studies will fall into this category.

\section{Other sources of potential bias}

\section{Low risk of bias}

The study appears to be free of other sources of bias.

\section{High risk of bias}

There is at least one important risk of bias. For example, the study:

- had a potential source of bias related to the specific study design used; or

- has been claimed to have been fraudulent; or

- had some other problem.

\section{Unclear}

There may be a risk of bias, but there is either:

- insufficient information to assess whether an important risk of bias exists; or

- insufficient rationale or evidence that an identified problem will introduce bias.

\section{CONTRIBUTIONSOF AUTHORS}

Hong-Tao Wang: conceived and designed the review; extracted data; checked the quality of data extraction; undertook and checked quality assessment; produced the first draft of the review; secured funding and approved the final review prior to submission.

Jin-Qiu Yuan: extracted data; checked the quality of data extraction; analysed or interpreted data; undertook and checked quality assessment; performed statistical analysis; contributed to writing and editing the review; made an intellectual contribution to the review; advised on the review and approved the final review prior to submission.

Bin Zhang: contributed to writing and editing the review; made an intellectual contribution to the review; advised on the review and approved the final review prior to submission.

Mao-Long Dong: contributed to writing and editing the review; made an intellectual contribution to the review; advised on the review and approved the final review prior to submission.

Chen Mao: checked the quality of the statistical analysis; contributed to writing and editing the review; made an intellectual contribution to the review; advised on the review and approved the final review prior to submission.

Da-Hai Hu: conceived, designed and coordinated the review; undertook and checked quality assessment; checked the quality of the statistical analysis; contributed to writing and editing the review; wrote to study author / experts / companies; approved the final review prior to submission and is a guarantor of the review.

\section{Contributions of the editorial base}

Jo Dumville and Nicky Cullum (Editors): edited the protocol; advised on methodology, interpretation, and protocol content; approved the final protocol prior to submission.

Kurinchi Gurusamy (Editor): edited the review; advised on methodology, interpretation, and review content; approved the final review prior to submission.

Gill Rizzello (Managing Editor): co-ordinated the editorial process; advised on content; edited the protocol and the review.

Reetu Child and Naomi Shaw (Information Specialists): designed the search strategy, ran the searches, and edited the search methods section.

Ursula Gonthier (Editorial Assistant): edited the plain language summary and reference sections.

\section{DECLARATIONSOF INTEREST}

Hong-Tao Wang: none known.

Jin-Qiu Yuan: none known. 
Bin Zhang: none known.

Mao-Long Dong: none known.

Chen Mao: none known.

Da-Hai Hu: none known.

\section{SOURCES OF SUPPORT}

\section{Internal sources}

- Natural Science Funds of Shaanxi Province China (2014JM4180), China.

\section{External sources}

- This project was supported by the National Institute for Health Research (NIHR), via Cochrane Infrastructure funding to Cochrane Wounds. The views and opinions expressed therein are those of the authors and do not necessarily reflect those of the Systematic Reviews Programme, NIHR, National Health Service (NHS), or the Department of Health, UK.

\section{DIFFERENCES BETWEEN PROTOCOLAND REVIEW}

Ulcer aetiology is a source of clinical heterogeneity we considered in the final review but did not state in the protocol.

In the protocol we planned to compare different forms of phototherapy and phototherapy of different output power, wavelength, power density, or dose range; however, as we did not identify any eligible studies reporting these comparisons, we did not carry out analyses for them.

Regarding unit of analysis issues, in the protocol we intended to combine effect estimates and their standard errors using the generic inverse-variance method. If unit of analysis issues had existed and we were unable to adjust for them, we planned to report them as part of the 'Risk of bias' assessment. However, we did not identify any included studies with the aforementioned unit of analysis issues in the final review.

We planned to evaluated publication bias in protocol, but did not do so because the number of included studies was less than 10.

\section{NDEX TERMS}

\section{Medical Subject Headings (MeSH)}

Diabetic Foot [ ${ }^{\star}$ therapy]; Foot Ulcer [therapy]; Phototherapy [adverse effects] [*methods]; Randomized Controlled Trials as Topic; Wound Healing

\section{MeSH check words}

Humans 